\title{
Theoretical and Experimental Results from Laboratory Tests by ILCM
}

\author{
M. Cardu (i) • A. Rispoli • G. Iabichino $\cdot$ P. Oreste $\cdot$ F. Vagnon
}

Received: 11 November 2020/Accepted: 17 January 2021 / Published online: 10 February 2021

(C) The Author(s) 2021

\begin{abstract}
The intermediate linear cutting machine (ILCM) is a machine designed to work on an intermediate scale between the full- and the smallscale. The reduced scale involves several advantages compared to full-scale tests, especially in terms of sample supplying and transportation. On the other hand, it has an impact on the testing conditions, resulting in a limitation of the cutting penetration and spacing during the test, as well as in a smaller disc cutter. This affects most of the results, which cannot be directly used for the on-site machine performance prediction. However, some experimental results provided in the literature show that the optimal spacing/ penetration ratio is not significantly affected by the changes involved. On this basis, the results obtained from ILCM tests should provide reliable information about the optimal cutting conditions of a tunnel boring machine in massive rock mass. The work performed included the development of some improvements of
\end{abstract}

M. Cardu $(\bowtie) \cdot$ P. Oreste

Environment, Land and Infrastructure Department, Politecnico, C.so Duca degli Abruzzi 24, 10129 Turin, Italy

e-mail: marilena.cardu@polito.it

M. Cardu - G. Iabichino $\cdot$ P. Oreste

IGG-CNR, Turin, Italy

A. Rispoli · F. Vagnon

Earth Sciences Department, University of Turin, Turin, Italy the testing rig, as well as a modified ILCM testing procedure, according to the one typically used in standard LCM tests. The results provide information about the attitude of the tested lithotypes to mechanical excavation by means of disc tools, including the optimal cutting conditions. Additional work was developed in terms of detailed characterisation of the rock samples involved and assessment of the size distribution of the debris produced during the ILCM tests. Nevertheless, further tests are necessary, in order to assess the consistency of the experimental procedure employed and to investigate the scale effect.

Keywords Tunnel boring machine - Disc tools . Linear cutting machine $\cdot$ Intermediate linear cutting machine $\cdot$ Optimal cutting conditions $\cdot$ Specific energy

\section{Introduction}

Excavation by tunnel boring machine (TBM) in hard rock is a very common technique, due to numerous advantages gained both in terms of time and development costs. The successful use of this technique goes through a proper design of the TBM cutterhead and cutters together with a reliable prediction of the machine performance, all of which are strongly dependent on the characteristics of the rock mass (Benato and Oreste 2015; Innaurato et al. 2011). 
As known, the full-scale rock cutting test by means of a linear cutting machine (LCM) is one of the most reliable methods in massive rock masses for predicting TBM performance as well as for optimising cutterhead design and defining the appropriate machine operating level.

The test involves the completion of a series of cuts by selecting both the cutting depth and spacing in advance. The cut is performed by holding the tool holder and moving longitudinally the sample box with a constant velocity. The action of the cutter, which is free to rotate around its axis, concerns the upper surface of the rock sample, which is exploited by progressive levels of cutting. During the test, the three orthogonal components of the force acting on the cutter are registered: the normal force $\left(\mathrm{F}_{\mathrm{N}}\right)$, the rolling force $\left(F_{R}\right)$ and the side force. The evaluation of the debris produced after each cut together with the $F_{R}$ allow defining the specific energy (SE). By performing a series of cuts with different cutting geometry, the optimum spacing/penetration ratio $(\mathrm{s} / \mathrm{p})_{\text {opt }}$ can be evaluated, namely the cutting geometry which involves the minimum consumption of specific energy.

LCM tests allow to define the penetration rates obtainable for a given operating level of the machine. In addition, they provide important information on the design of the cutterhead layout as well as the required thrust and torque. The results obtained are particularly reliable under massive rock conditions, while further research developments are needed to adapt the results of laboratory tests in highly fractured rock formations (Balci 2009).

Among the studies from the literature, Roxborough and Rispin (1973) performed a series of rock cutting tests with different types of cutters, diameters and cutting geometries on Lower Chalk. Roxborough and Phillips (1975) performed numerous linear cutting tests on Bunter Sandstone using V-type discs with different sizes and tip angles, varying the cutting geometry. Snowdon et al. (1982) defined the (s/p) opt ratio for different rock types. Sanio (1985) evaluated the effect of rock anisotropy on the cutting process.

Rostami and Ozdemir (1993) used a large database of LCM test results to define the average pressure in the rock/tool contact area to be included in the formulation of the CSM model. Bilgin et al. (1999) used the results obtained from full-scale rock-cutting tests to predict TBM performance in the excavation of the Tuzla-Dragos sewer tunnel, Istanbul. Bilgin et al. (2005), through the results of LCM tests, evaluated the optimal cutting conditions and the related production rate for a TBM used for the excavation of a tunnel in sedimentary rock.

Chang et al. (2006) defined the (s/p) opt ratio for a Korean granite. Balci and Bilgin (2007) compared the results obtained from full-scale tests with those achieved by small-scale tests. Gertsch et al. (2007) evaluated the specific energy and cutting forces through a series of LCM tests with a $17^{\prime \prime}$ CCS disc on granite. Balci (2009) compared the results from full-scale tests with the TBM performance in fractured rock masses. Bilgin et al. (2008) provided the cutterhead design and performance prediction for a tunnel project in Istanbul. Cho et al. (2010) used the results of LCM tests to develop a numerical model to simulate the rock cutting process with a disc cutter. Balci and Tumac (2012) compared the results of LCM tests with on-site performance and theoretical models to investigate the rock cuttability by V-type discs. Cho et al. (2013) performed LCM tests on granites using a photogrammetric method to measure the debris produced. Abu Bakar et al. (2014) analysed the relationship among debris size, specific energy and cutting geometry obtained from LCM tests on sandstone. Copur et al. (2014) used the results of full-scale tests for evaluating the performance of two EPB TBMs by a stochastic approach. Tumac and Balci (2015) used, in addition to the results of other studies, the results of LCM tests on three different rock types to develop an empirical model for the evaluation of the forces acting on a CCS disc cutter. Yin et al. (2016) used the results of LCM tests to analyse the effect of joint spacing on the rock-cutting process. Pan et al. (2019) compared the results of full-scale linear cutting tests, using a $432 \mathrm{~mm}$ CCS disc cutter in Chongqing Sandstone, with field TBM data, for excavation performance prediction. Pan et al. (2020) performed full-scale linear cutting tests to check and modify a widely used semi-theoretical model for disc cutter cutting force prediction.

Nevertheless, to carry out full-scale linear cutting tests, a size of the rock samples of around $0.5 \mathrm{~m}^{3}$ is necessary: indeed, supplying samples of such size may be quite difficult and expensive; the big size of the samples may also involve several problems in terms of transportation, handling and positioning. 
To overcome these limitations, some testing methods with a reduced scale were developed (e.g. Rad 1975; McFeat-Smith and Fowell 1977; Balci and Bilgin 2007; Innaurato et al. 2007; Bilgin et al. 2010; Entacher et al. 2014; Liu et al. 2016). A number of them consist of indentation tests, which, however, are not able to simulate the rock-breaking mechanism by disc cutters in detail; others involve the disc rolling, but the large differences in terms of scale or testing conditions may seriously affect the reliability of the results when they are used for on-site performance prediction. In this regard, a machine called Portable Linear Cutting Machine (PLCM) was developed at the Istanbul Technical University, providing results that are comparable to those obtained by LCM (Bilgin et al. 2010, 2013; Balci and Tumac 2012): this machine can be equipped with a $5.1^{\prime \prime}$ mini-disc and can be used on smaller-sized samples (e.g. $0.2 \times 0.2 \times 0.1 \mathrm{~m})$. The PLCM minimizes some of the disadvantages of full-scale linear rock cutting machine (FLCM) such as requiring experienced manpower to run the tests, large blocks of rock samples, which are usually difficult to obtain and expensive, and time consuming procedures (Komakli et al. 2020).

To develop a method that would combine the reliability of a full-scale rock cutting test with the convenience of a small-scale method, the Environment, Land and Infrastructures Department (DIATI) of the Politecnico di Torino, in collaboration with the Institute of Geosciences and Georesources of the National Research Council (CNR-IGG), developed the so-called Intermediate Linear Cutting Machine (ILCM); it was designed as an LCM for use on rock samples with an intermediate size between full-scale tests (e.g. ten times larger) and PLCM (e.g. ten times smaller).

The reduced size of the rock samples involves considerable advantages compared to standard fullscale tests. First, the supply is easier: the rock sample can be obtained in a simpler way directly from the rock mass under excavation, but also from an irregular block found in the rock outcrops near the tunnel portal. Rock blocks with the required size can also be found in neighbouring quarries, if present, and can be easily shaped. Moreover, the transportation is cheaper and can be achieved by a standard vehicle. Sample handling and positioning can be done by a rather small rig.
The change of the sample size has an impact on the testing conditions. Indeed, to carry out a series of adjacent cuts without incurring edge effects, a limitation of the disc penetration and cut spacing are required. Such requirements suggest using a disc that is smaller than those typically used on-site.

The reduction of cutting geometry and cutter size in ILCM tests involves a change in terms of cutting forces and specific energy which, consequently, cannot be used directly for predicting the on-site machine performance.

Experimental results from some literature studies show that $(\mathrm{s} / \mathrm{p})_{\text {opt }}$ is quite independent of the changes made. In particular, the results obtained by Roxborough and Phillips (1975) show that the reduction of the disc diameter involves a reduction of the normal cutter force but does not significantly affect the rolling force, the volume produced and, consequently, the specific energy.

Snowdon et al. (1982) also found that the optimum $(\mathrm{s} / \mathrm{p})$ ratio is independent of the cutting penetration.

Another aspect is the type and edge angle of the disc cutter employed. In fact, in order to further reduce the cutting forces during the test, a V-type disc is typically mounted on the ILCM. This involves different cutting performance compared to those obtained by the constant cross section (CCS) disc cutter used on-site (Tumac and Balci 2015). However, once again, some studies proved that $(\mathrm{s} / \mathrm{p})_{\text {opt }}$ is not significantly affected by these changes. In fact, Bilgin et al. (1999) found that, all parameters being equal, CCS and V-type discs show a similar Specific Energy (SE) trend. The results obtained by Roxborough and Phillips (1975) also show that the optimum ( $\mathrm{s} / \mathrm{p}$ ) ratio is not affected by the variation of the edge angle, except for an angle of $100^{\circ}$, which results in a slight increase of the $(\mathrm{s} / \mathrm{p})_{\text {opt }}$.

On this basis, the results obtained from ILCM tests should provide reliable information about the on-site optimal cutting condition in massive rock mass. As for the cutting forces acting on the cutters, they are subject to a scale effect passing from ILCM to on-site conditions; however, they may still be reliably estimated by some analytical prediction models.

Nonetheless, further experimental analysis should be performed to investigate in detail the impact of the differences between on-site and laboratory cutting conditions. If necessary, a correction factor should be obtained to adapt the results from ILCM to the actual TBM. 
In the following, the results of a series of tests carried out on two types of rock are described. The work performed also included some changes made to improve the testing conditions and, consequently, the reliability of the results.

In particular, compared to the first ILCM tests reported in Rispoli (2013) and Cardu et al. (2017a, b), the improvements adopted concern cutter edge profile, sample containment and testing procedure.

\section{Test Equipment}

\subsection{ILCM Structure}

The Intermediate Linear Cutting Machine built at the Politecnico di Torino and its main components are shown in Fig. 1. The bearing structure of the ILCM consists of a solid steel frame that includes two coupled HEB beams arranged vertically, a transverse beam housed inside the portal and a longitudinal beam.

The vertical beams include three levels of housing for the transverse beam, at a distance of about $300 \mathrm{~mm}$, allowing the installation of a wide range of disc diameters and the accommodation of rock samples with different thickness. The vertical movement of the tool holder is obtained by a piston contained in a vertical cylinder and driven by a $1.5-\mathrm{kW}$ electric motor, which acts on an endless screw with a stroke of $300 \mathrm{~mm}$.

The movement of the piston during the test can be prevented by an appropriate locking mechanism made of two bolts, or cranks, located on the external cylinder. A triaxial load cell is mounted between the piston and the tool holder.

Currently, a 6.7" V-type disc is mounted on the tool holder, which can also be equipped with a Plexiglas cap to prevent debris ejecting. The sample-holding structure consists of a sample steel box, which can host a sample with a maximum base area of $890 \times 470 \mathrm{~mm}$ and can be translated longitudinally (e.g. cutting direction) and transversally.

The longitudinal movement of the sample box along the guides of the longitudinal beam is provided by a mechanical jack driven by a $15-\mathrm{kW}$ electric motor, which allows a cutting speed of about $1.5 \mathrm{~cm} / \mathrm{s}$.

The transversal translation for setting the cut spacing is obtained through a manually operated threaded screw. The control of the two motors is obtained through an electric panel, which also includes a remote control.

\subsubsection{Disc Cutter}

At first, a $6.5^{\prime \prime}$ V-type disc, produced by the Robbins Company, with an edge angle of about $152^{\circ}$ was mounted on the ILCM. Such wide angle involved a quite high normal cutter force acting on the disc, and the cutter thrust capacity was already reached for low values of cutter penetration. This condition affected the comprehensiveness of the tests, by requiring cutter penetration that was generally lower than $4 \mathrm{~mm}$.

For this reason, a $6.7^{\prime \prime} \mathrm{V}$-type disc with a $60^{\circ}$ edge angle was mounted. The comparison between the previous and current disc is shown in Fig. 2.

The sharper disc profile allows, compared to the previous cutter, a considerable reduction of the normal force for a given cutter penetration.

In order to avoid a premature damage of the roller bearing, an average cutter force lower than $50 \mathrm{kN}$ and a peak cutter force lower than $100 \mathrm{kN}$ are recommended.

\subsubsection{Sample Containment}

In the first tests carried out by ILCM, the sample was fixed on the box by means of small rock blocks and wood wedges inserted at the base of the sample. However, this solution involved several issues: first, such containment method only affected the lower portion of the sample, and hence the contrast forces were not evenly distributed over the lateral surface of the sample. This induced the detachment of rock pieces near the sample edges at the rock/sample contact area, and, sometimes, the creation of deep cracks in the rock sample, making it unusable for the test. Moreover, the sample fixing only occurred in the cutting direction, enabling transversal movements, especially during the execution of the external cuts. In order to overcome these limitations, another method was adopted, according to the available equipment. In particular, the rock sample was cast within the sample box, as shown in Fig. 3. Once the grout is hardened, the sample is completely fixed by using bar clamps. 


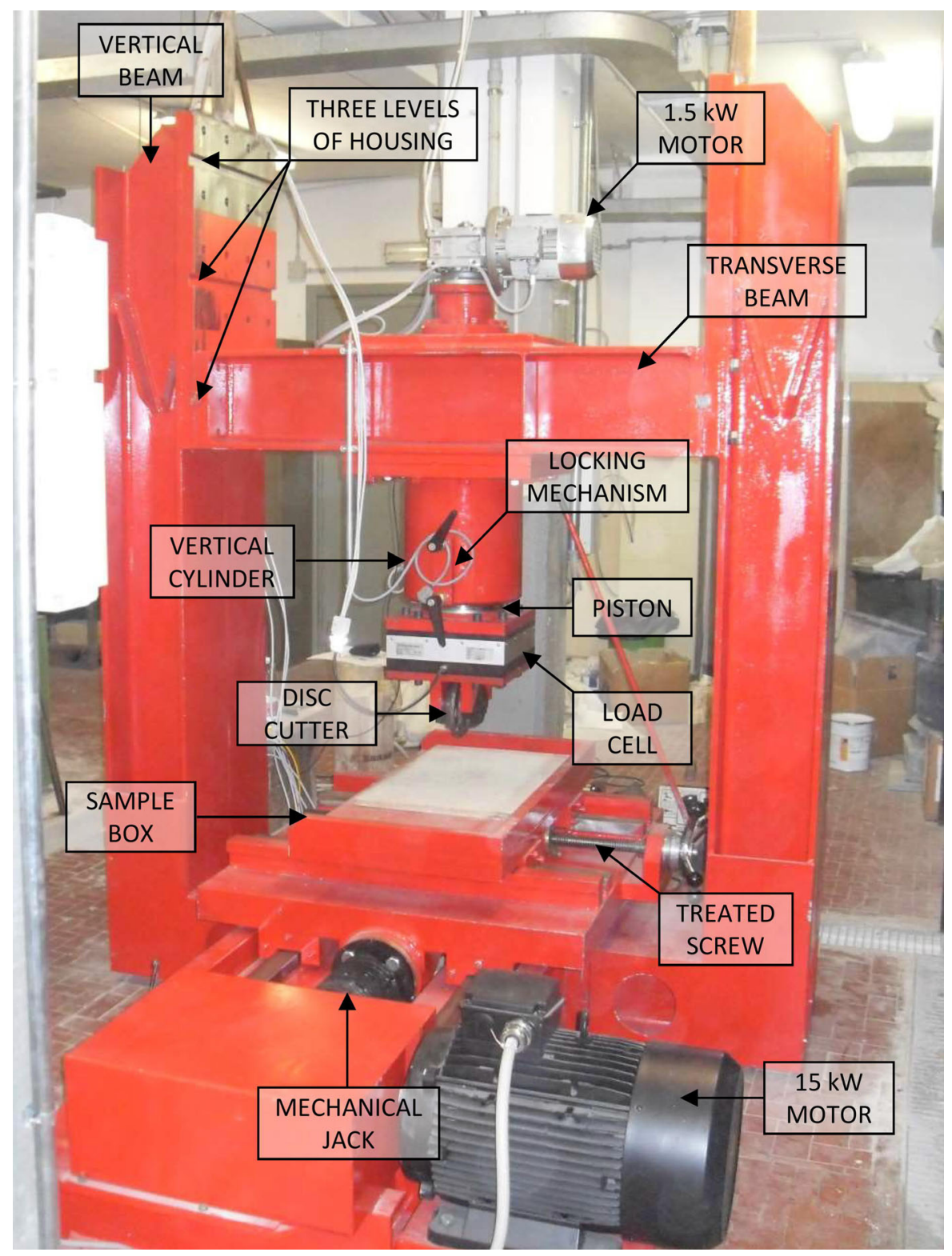

Fig. 1 ILCM and its main components (Revised from Cardu et al. 2017a, b)

\subsubsection{Acquisition System}

The acquisition system of the ILCM allows the measurement of the following parameters:

- Three components of the force acting on the disc;

- Longitudinal displacement of the sample box;

- Vertical displacement of the piston.

The three components of the cutting force, namely the normal cutter force $\left(\mathrm{F}_{\mathrm{N}}\right)$, the rolling cutter force $\left(\mathrm{F}_{\mathrm{R}}\right)$ and the side force $\left(\mathrm{F}_{\mathrm{S}}\right)$, are measured by the triaxial load cell, which has a range of $100 \mathrm{kN}$ in the horizontal directions (sensitivity around $0.2 \mathrm{kN}$ ) and $200 \mathrm{kN}$ in the vertical direction (sensitivity around $0.3 \mathrm{kN}$ ). The load cell was calibrated by means of a controlled stress path performed in a load frame, as reported by Rispoli (2013).

The longitudinal displacement of the sample box is measured by a wire-type displacement transducer, which has a range of $2.032 \mathrm{~m}$ and a sensitivity of 
PREVIOUS DISC

\section{CURRENT DISC}
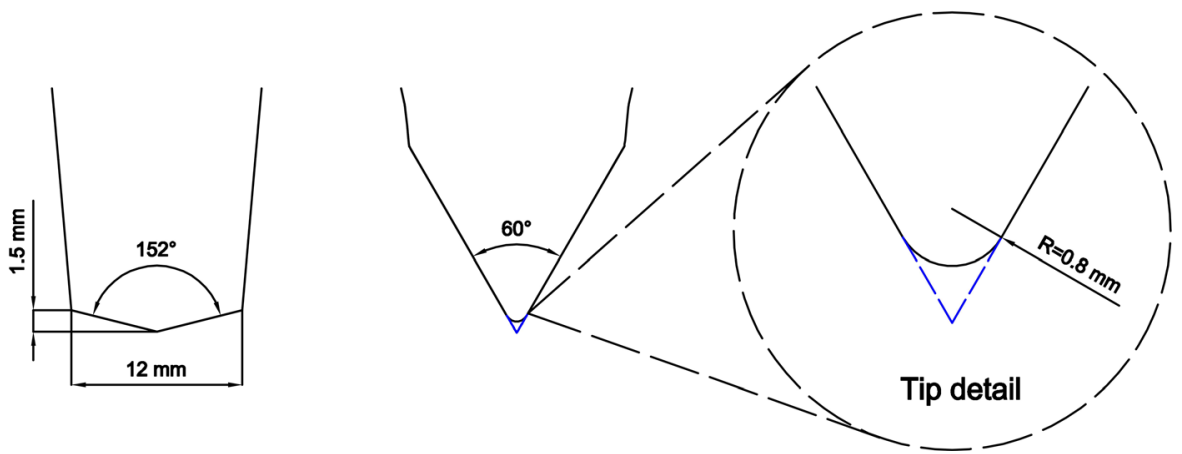

Fig. 2 Comparison between the previous (left) and current (right) edge profile of the disc mounted on the ILCM
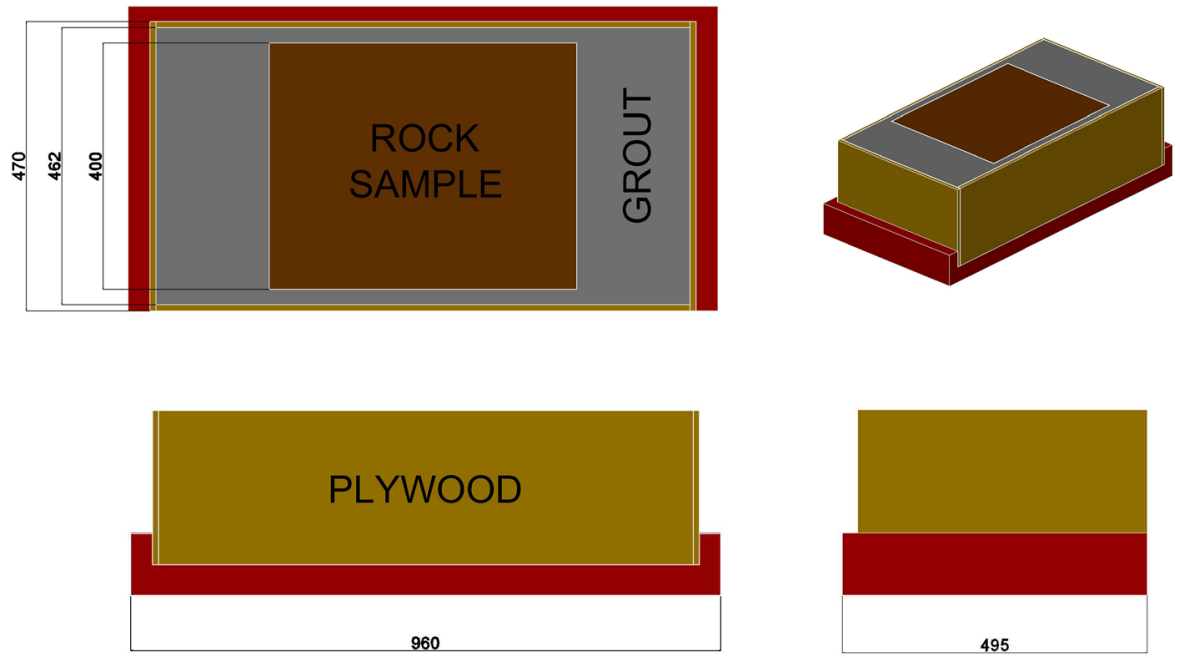

Fig. 3 Scheme of the sample containment (dimensions in $\mathrm{mm}$ )

around $0.3 \mathrm{~mm}$. The longitudinal displacement is especially useful in the data processing phase, to detect the portion of the sample to be used for the calculation.

Originally, the ILCM was equipped with a wiretype transducer for measuring the vertical displacement of the piston, which coincides with the vertical displacement of the disc cutter. However, since low values of penetrations are involved in the ILCM tests, an improvement in the measurement accuracy of the cutting penetration became necessary, and hence an inductive displacement transducer with a range of $10 \mathrm{~mm}$ and a sensitivity of $0.01 \mathrm{~mm}$ was introduced. In particular, as shown in Fig. 4, an aluminium frame was specially designed to place the transducer, enabling the measurement of the piston displacement in relation to the external cylinder. In this way, the cutter penetration could be carefully checked before the cutting, but also during the test.

The machine allows the acquisition of all the electrical signals measured by an electronic system (Spider8) developed by HBM Company, which is connected to a PC located near the ILCM. The signal processing is provided by a dedicated software called Catman (HBM Company), which allows, inter alia, to set the acquisition frequency of the acquired signals and to export data for processing. 


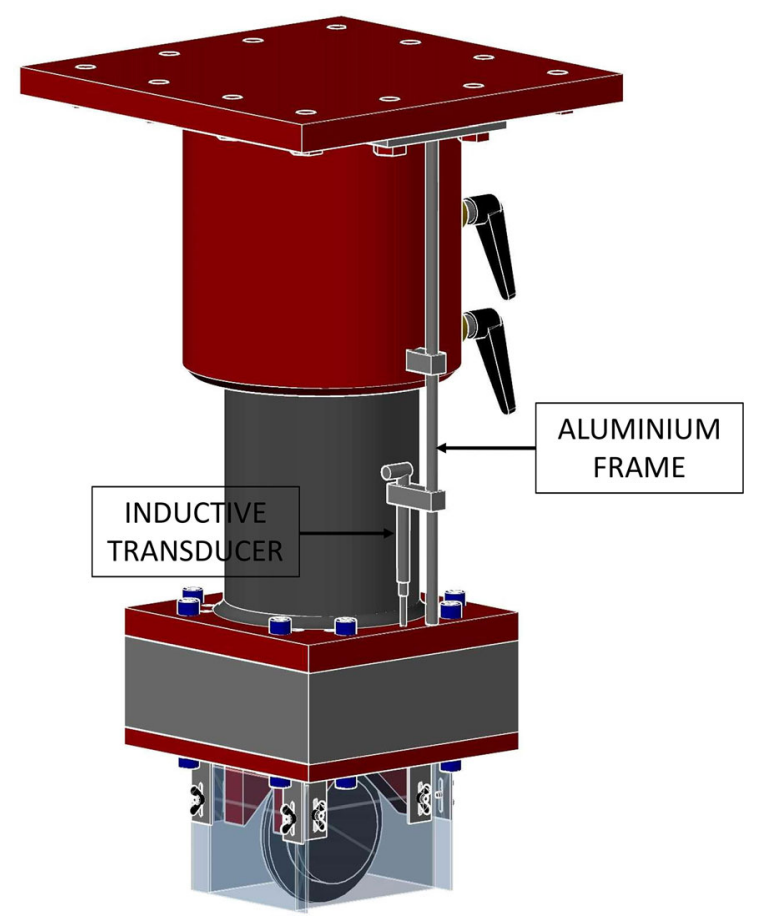

Fig. 4 View of the ILCM with the aluminium frame used for positioning the inductive transducer that measures the vertical displacement of the cutter

\section{Experimental Procedure}

In the first tests carried out by ILCM and reported by Rispoli (2013) and Cardu et al. (2017a, b), the testing procedure was quite different from that currently employed. In particular, the previous tests only involved the exploitation of the upper surface of the sample, which had been rectified before the tests. As a result, all the cuts were performed on a single level by keeping the cutter penetration constant and varying the spacing. This solution was required because of the above-mentioned issues related to the method previously adopted for the sample containment, and involved several limitations:

- Reduced exploitation of the sample;

- Cutting on a flat surface, which is not representative of the on-site cutting condition;

- Change of the effective cutting penetration during the test due to the not perfect flatness of the sample upper surface;

- Only one cut could be tested for each cutting geometry.
For these reasons, a new testing procedure was developed, thanks to the previously mentioned improvements related to the cutter and sample containment. Such testing procedure is inspired by the methodology commonly adopted at the ITU (Istanbul Technical University) laboratories for the full-scale rock cutting tests (e.g. Bilgin et al. 2005, 2008, 2013; Balci and Tumac 2012; Entacher et al. 2015): it involves a greater exploitation of the sample by means of progressive cutting levels; moreover, the cuts are performed on a preconditioned surface, namely on a groove that was already created in a previous cutting level.

\subsection{Sample Setting}

Before starting the test, the sample must be properly arranged. First, it is moved to the box by means of a hydraulic floor crane. Then, a dedicated plywood framework is placed on the sample box, covered with a plastic sheet, and sealed with silicon. The sample is cast with a mineral-aggregate grout, which is mixed for a few minutes by a mortar mixer and immediately poured into the framework. After waiting $48 \mathrm{~h}$, the grout curing is completed, and the bar clamps can be applied to completely fix the rock sample in the box. Some steps of the sample preparation are shown in Fig. 5.

As mentioned above, in order to reproduce the onsite conditions, the cutting tests are carried out on a pre-conditioned surface. For this reason, the sample preparation also includes the conditioning of the first levels of the sample (Fig. 6), which involves a series of trimming cuts to eliminate possible unevenness in the upper sample surface, and some conditioning cuts to set the desired spacing between the cuts, which is kept constant in all the cutting levels performed. During this phase, the evaluation of the cutting parameters may provide preliminary information on the adequacy of the cutting geometry chosen, thereby allowing any adjustments.

\subsection{Test Execution}

A typical layout of a cutting test carried out by ILCM is shown in Fig. 7. Each cutting level is indicative of a single cutting geometry (e.g. spacing/penetration ratio) since the penetration and spacing of the cuts are kept constant within the same level. The spacing 

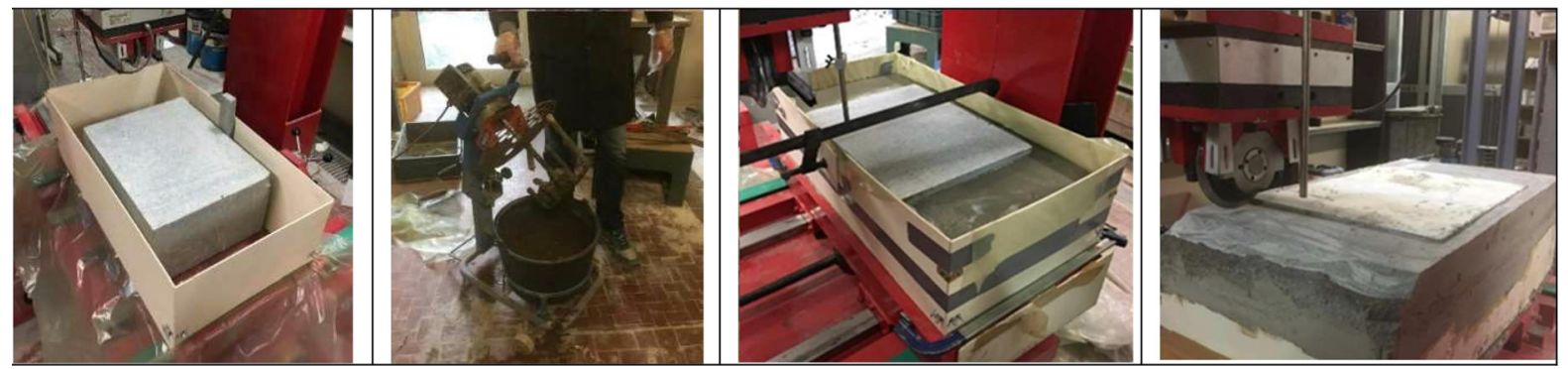

Fig. 5 Some steps of the sample preparation

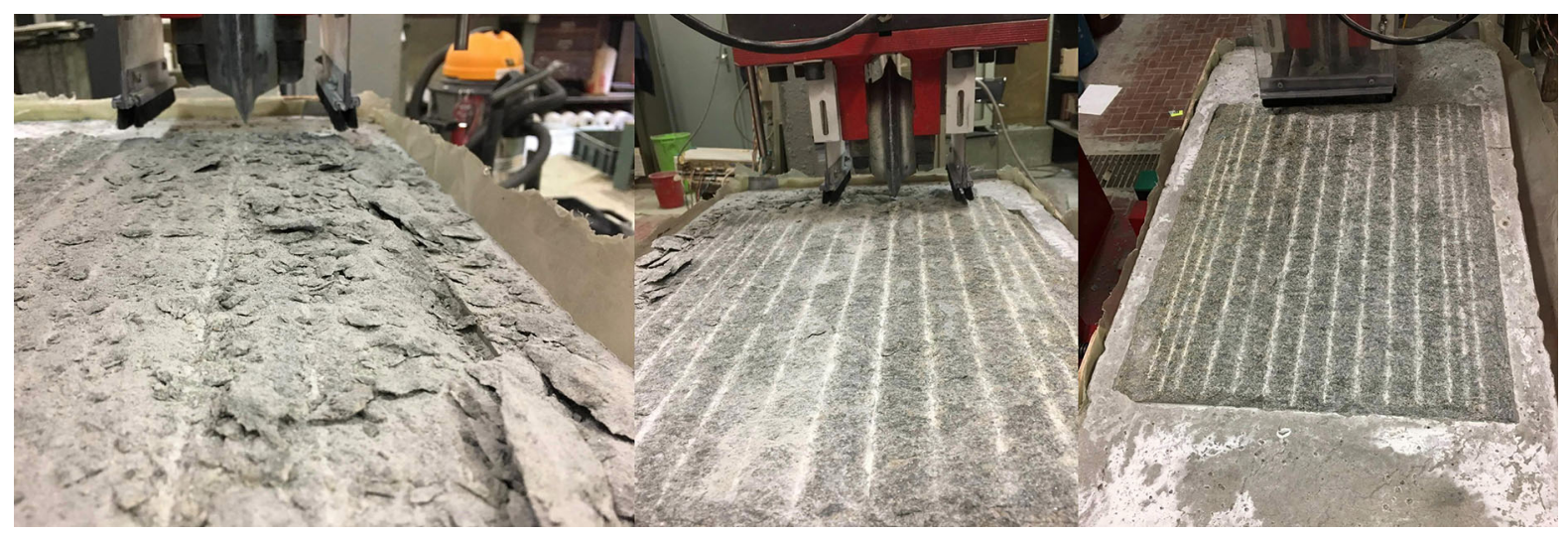

Fig. 6 Sample conditioning

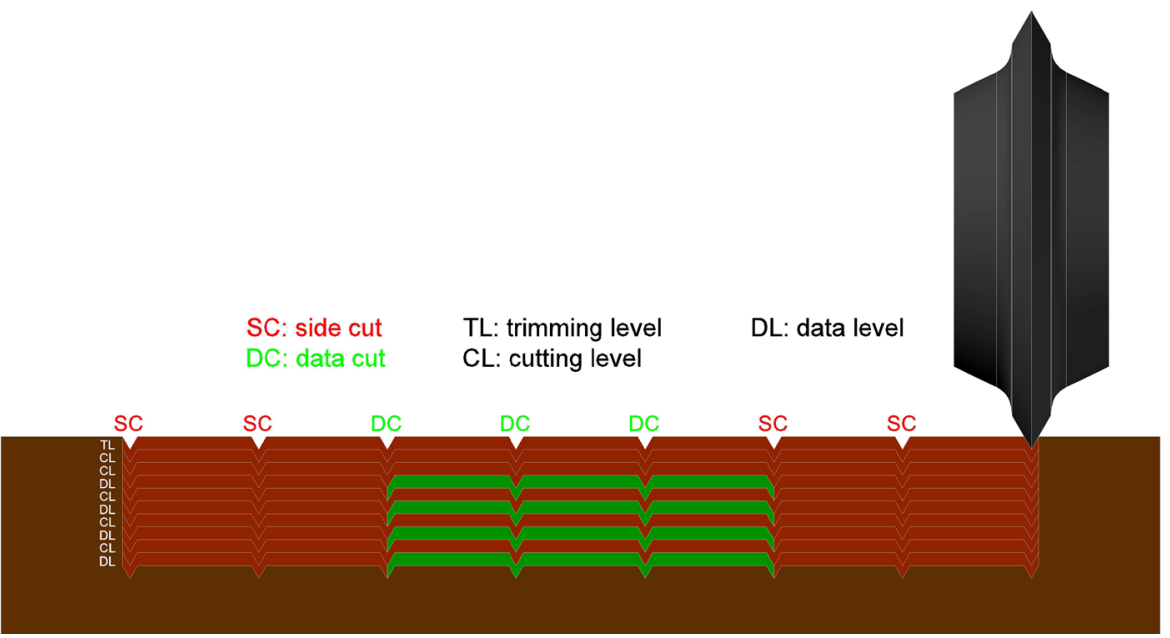

Fig. 7 Example of a testing layout during ILCM tests. In green: portions of the sample actually used for the calculations. In red: portions of the sample that are subject to trimming, conditioning or side cuts

between the cuts is the same for the whole test, whereas the cutter penetration can be changed from one level to another, allowing the assessment of different cutting geometries. Before starting the tests in each level that will be used for the calculations (data level), one or more conditioning levels should be performed with the chosen cutting penetration, avoiding any effect related to the cutting geometry of the 
previous data levels. In each data level, the side cuts are not used for the calculation, in order to disregard the effects of the sample edges.

Before performing each cutting level, the cutting penetration is set by lowering the vertical piston and checking the measure taken by the inductive transducer. Then, the piston is fixed on the external cylinder by tightening the bolts of the locking mechanism through a torque wrench. In this way, the vertical displacements of the cutter during the tests are extremely reduced. At this point, the cutting penetration is set, and the cutting level can be performed.

The rock cutting is always made according to the same direction and sequence of cut, in order to avoid consequences due to methodological changes. In fact, the effects of a possible rock anisotropy should not be assessed on a single sample, but through several cutting tests, by arranging appropriate rock samples. After each cut, the cutter is moved back down along the groove just crossed, and then it is moved laterally by acting on the threaded screw, according to the chosen spacing. Then, after removing the debris produced, a new cut can be performed. When the last cut of the cutting level is carried out, the locking system can be loosened, and a new cutter penetration can be set.

The debris is collected by a vacuum, stored in a sampling bag and properly catalogued for the following analysis. To consider only the debris related to the tested cutting length, the sample portions to be excluded are marked by means of crayons (Fig. 8).

\subsection{Data Processing}

After performing each cut, the data acquired are exported by the Catman software and stored in text files. The data processing is generally implemented by Microsoft Company (2020), and includes the assessment of the relevant parameters within the portion of the sample tested. In this regard, a series of VBA codes were created in Excel by the Macro Recorder, in order to automatically perform the processing operations and to provide the results (Fig. 9).

The relevant parameters assessed through the tests are summarised in Table 1.

\section{Tests Performed on Carrara Marble and Luserna Gneiss}

The tests described in this study were performed on samples of two metamorphic rocks (Northern Italy): Carrara marble and Luserna gneiss. In the following, a brief description of the two types of rocks is provided.

The Carrara marble sample, with a size of $500 \times 400 \times 250 \mathrm{~mm}$, was provided by the quarry called "Gioia" in the Tuscany region (Italy). This type of marble, commercially known as Bianco Venato Gioia, is on average isotropic, and its mechanical properties, obtained in the laboratory as an average of 10 tests for each of the characteristics investigated, are shown in Table 2.

The Luserna gneiss sample was supplied from a quarry in the municipality of Luserna San Giovanni, Turin (Italy). The sample has dimensions

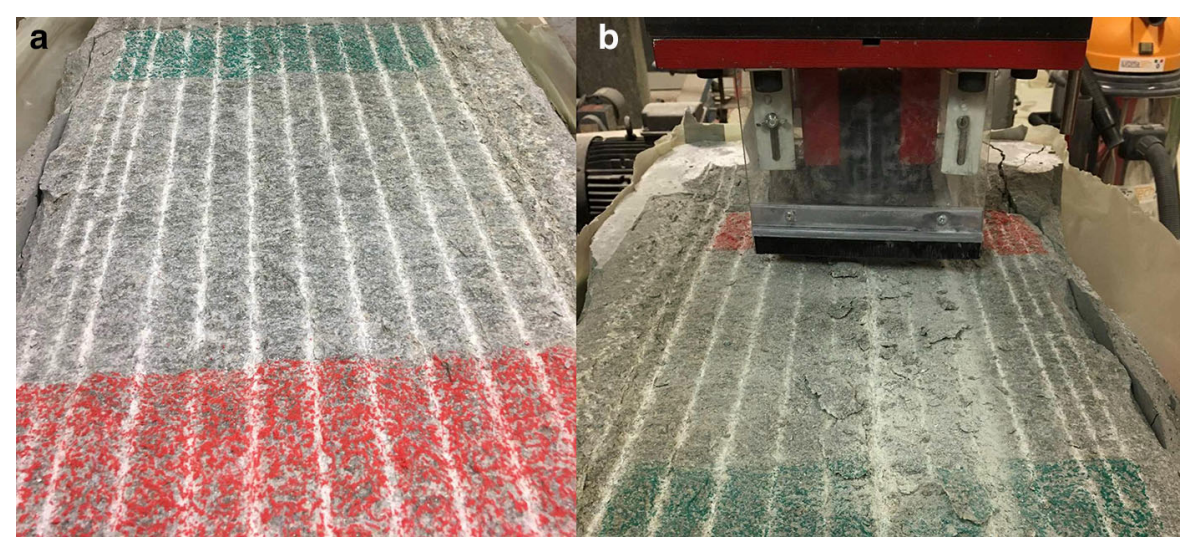

Fig. 8 Some steps of the execution of a data level: marking the sample portion to be excluded from the calculations (a), performing the data cut and collecting the debris that is not marked (b) 


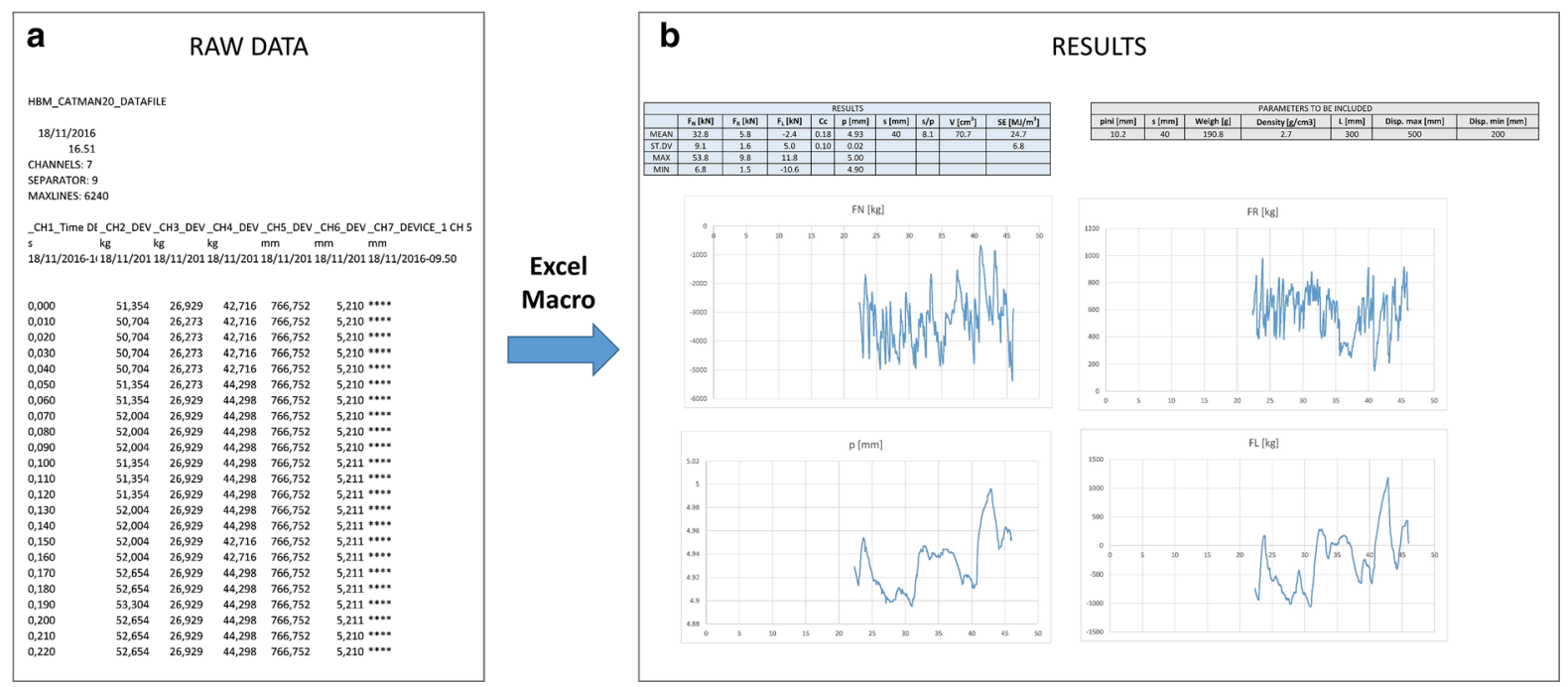

Fig. 9 Screenshots of the Excel sheet before (a) and after (b) using the Macro specifically created

Table 1 Parameters assessed through the ILCM test

\begin{tabular}{llllll}
\hline Parameter & Symbol & Unit & Parameter & Symbol & Unit \\
\hline Cutting penetration & $\mathrm{p}$ & $\mathrm{mm}$ & Cutting coefficient $\mathrm{F}_{\mathrm{R}} / \mathrm{F}_{\mathrm{N}}$ & $\mathrm{Cc}$ & - \\
Cut spacing & $\mathrm{s}$ & $\mathrm{mm}$ & Penetration index $\mathrm{F}_{\mathrm{N}} / \mathrm{p}$ & $\mathrm{PI}$ & $(\mathrm{kN} / \mathrm{mm})$ \\
Spacing/penetration & $\mathrm{s} / \mathrm{p}$ & - & Debris volume & $V$ & $\mathrm{~cm}^{3}$ \\
Average normal cutter force & $\mathrm{F}_{\mathrm{N}}$ & $\mathrm{kN}$ & Testing length & $1_{\text {data }}$ & $\mathrm{mm}$ \\
Peak normal cutter force & $\mathrm{F}_{\mathrm{Nmax}}$ & $\mathrm{kN}$ & Specific energy & $\mathrm{SE}$ & $\mathrm{MJ} / \mathrm{m}^{3}$ \\
Average rolling cutter force & $\mathrm{F}_{\mathrm{R}}$ & $\mathrm{kN}$ & Optimum s/p & $(\mathrm{s} / \mathrm{p})_{\mathrm{opt}}$ & - \\
Peak rolling cutter force & $\mathrm{F}_{\mathrm{Rmax}}$ & $\mathrm{kN}$ & & & \\
\hline
\end{tabular}

Table 2 Mechanical properties of Carrara Marble

\begin{tabular}{lll}
\hline Parameter & Unit & Average value \\
\hline Density & $\mathrm{kg} / \mathrm{m}^{3}$ & 2695 \\
Uniaxial compressive strength & $\mathrm{MPa}$ & 79 \\
Brazilian tensile strength & $\mathrm{MPa}$ & 14 \\
Elastic modulus (tangent) & $\mathrm{MPa}$ & 42.6 \\
Elastic modulus (secant) & $\mathrm{MPa}$ & 33.8 \\
P-wave velocity (average) & $\mathrm{m} / \mathrm{s}$ & 4413 \\
S-wave velocity (average) & $\mathrm{m} / \mathrm{s}$ & 2634 \\
Young's modulus $E=2 G(1+v)$ & $\mathrm{GPa}$ & 45.7 \\
Shear modulus $G=\rho V_{S}^{2}$ & $\mathrm{GPa}$ & 18.7 \\
\hline
\end{tabular}

$500 \times 400 \times 250 \mathrm{~mm}$. The lithotype has a finegrained gray/greenish background. It can show scattered white crystals, whose dimensions generally amount to several millimetres. The rock shows an evident schistosity which, however, does not involve a relevant anisotropy in terms of mechanical properties. In this regard, its mechanical properties are better than those of Carrara marble, as shown in Table 3.

Table 3 Mechanical properties of the Luserna gneiss

\begin{tabular}{lll}
\hline Parameter & Unit & Average value \\
\hline Density & $\mathrm{kg} / \mathrm{m}^{3}$ & 2611 \\
Uniaxial compressive strength & $\mathrm{MPa}$ & 208 \\
Brazilian tensile strength & $\mathrm{MPa}$ & 31 \\
Elastic modulus (tangent) & $\mathrm{MPa}$ & 56.7 \\
Elastic modulus (secant) & $\mathrm{MPa}$ & 38.9 \\
P-wave velocity (average) & $\mathrm{m} / \mathrm{s}$ & 4499 \\
S-wave velocity (average) & $\mathrm{m} / \mathrm{s}$ & 2757 \\
Young's modulus $E=2 G(1+v)$ & $\mathrm{GPa}$ & 47.6 \\
Shear modulus $G=\rho V_{S}^{2}$ & $\mathrm{GPa}$ & 19.9
\end{tabular}


The testing layout was chosen on the basis of the assessment of the optimal spacing/penetration ratio. However, the sample size and the cutter load capacity should also be taken into account: the cutting sequence was designed in order to perform the first levels with a lower $\mathrm{s} / \mathrm{p}$ ratio and then to gradually decrease the penetration until reaching the $(\mathrm{s} / \mathrm{p})_{\mathrm{opt}}$. The results obtained from the first trimming and conditioning levels showed that a cutting spacing of $40 \mathrm{~mm}$ is appropriate for the purpose of the test and allows a good exploitation of the sample surface without exceeding the cutter load capacity. An s/p ratio ranging from 7.3 to 11.4 was enough to detect the optimal cutting condition. Five data levels with a cutting penetration range between 3.5 and $5.5 \mathrm{~mm}$ were performed. The change of the cutting penetration applied between the data levels was typically around $0.5 \mathrm{~mm}$ and never exceeded $1 \mathrm{~mm}$. In this way, only one conditioning level was necessary before performing each data level. A testing length of $300 \mathrm{~mm}(60 \%$ of the total cut length) was considered. On the basis of the spacing chosen, two cuts for each data level were used for the calculations, in order to avoid sample edge effects. The testing layout is summarised in Table 4, and the data level layout is shown in Fig. 10.

Similar to above, the testing layout was selected according to the range of $(\mathrm{s} / \mathrm{p})$ required to assess the optimal cutting condition. However, the better mechanical properties of the Luserna gneiss led to some changes compared to the previous test. In particular, the first cutting levels showed, as expected, a considerable increase of the cutting forces for a given cutting geometry; on this basis, a reduction of the

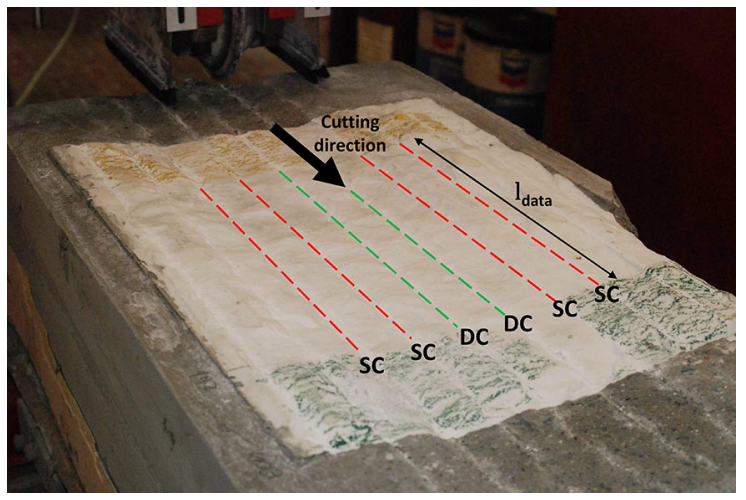

Fig. 10 Data level layout used on the Carrara marble sample. $\mathrm{SC}=$ side cut, $\mathrm{DC}=$ data cut, $1_{\mathrm{data}}=$ testing length

cutting penetration and, consequently, of the spacing was required in order not to damage the disc cutter. A spacing of $30 \mathrm{~mm}$ and a starting penetration around $4.5 \mathrm{~mm}$ were chosen. A decrease of about $0.5 \mathrm{~mm}$ was then applied between one data level and the other until the $(\mathrm{s} / \mathrm{p})_{\text {opt }}$ was assessed. Six data levels with a cutting penetration ranging from 4.3 to $1.8 \mathrm{~mm}$ were performed. The testing length was, once again, $300 \mathrm{~mm}$. The lower cut spacing allowed analysing four data cuts for each data level. In this regard, the Luserna gneiss showed a greater difference in the cutting parameters between one data cut and the other, compared to Carrara marble. For this reason, the increase of the number of cuts was useful to improve the reliability of the results. The testing layout employed is summarised in Table 5, and the data level layout is shown in Fig. 11.
Table 4 Testing layout adopted (Carrara marble sample)

\begin{tabular}{llllll}
\hline Level No & Level type & $\mathrm{p}(\mathrm{mm})$ & $\mathrm{s}(\mathrm{mm})$ & $\mathrm{s} / \mathrm{p}$ & $1_{\text {data }}(\mathrm{mm})$ \\
\hline 1 & Trimming & 4.2 & - & 9.5 & - \\
2 & Conditioning & 5.0 & 40 & 8.0 & - \\
3 & Conditioning & 5.1 & 40 & 7.9 & - \\
4 & Data & 4.9 & 40 & 8.1 & 30 \\
5 & Conditioning & 5.5 & 40 & 7.2 & - \\
6 & Data & 5.5 & 40 & 7.3 & 30 \\
7 & Conditioning & 4.5 & 40 & 8.9 & - \\
8 & Data & 4.5 & 40 & 9.0 & 30 \\
9 & Conditioning & 3.9 & 40 & 10.3 & - \\
10 & Data & 4.0 & 40 & 10.1 & 30 \\
11 & Conditioning & 3.5 & 40 & 11.4 & - \\
12 & Data & 3.5 & 40 & 11.4 & 30 \\
\hline
\end{tabular}


Table 5 Testing layout used on the Luserna gneiss sample

\begin{tabular}{llllll}
\hline Level No & Level type & $\mathrm{p}(\mathrm{mm})$ & $\mathrm{s}(\mathrm{mm})$ & $\mathrm{s} / \mathrm{p}$ & $1_{\text {data }}(\mathrm{mm})$ \\
\hline 1 & Trimming & 1.8 & - & - & - \\
2 & Trimming & 2.8 & - & - & - \\
3 & Conditioning & 2.9 & 30 & 10.3 & - \\
4 & Conditioning & 4.4 & 30 & 6.8 & - \\
5 & Data & 4.3 & 30 & 7.0 & 300 \\
6 & Conditioning & 3.9 & 30 & 7.7 & - \\
7 & Data & 3.7 & 30 & 8.0 & 300 \\
8 & Conditioning & 3.4 & 30 & 8.8 & - \\
9 & Data & 3.3 & 30 & 9.0 & 300 \\
10 & Conditioning & 3.0 & 30 & 10.0 & - \\
11 & Data & 2.8 & 30 & 10.7 & 300 \\
12 & Conditioning & 2.4 & 30 & 13.0 & - \\
13 & Data & 2.3 & 30 & 12.9 & 300 \\
14 & Conditioning & 1.9 & 30 & 15.8 & - \\
15 & Data & 1.8 & 30 & 16.3 & 300 \\
\hline
\end{tabular}

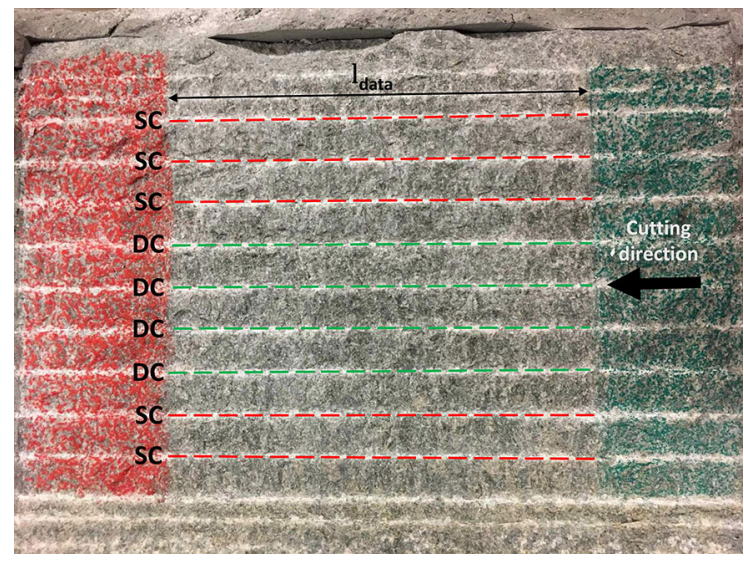

Fig. 11 Data level layout used on the Luserna gneiss sample. $\mathrm{SC}=$ side cut, $\mathrm{DC}=$ data cut, $1_{\text {data }}=$ testing length

The tests carried out allowed obtaining the grain size distribution of the debris produced during the data acquisition levels. Each level is made up of several grooves having the same spacing (s) and penetration (p). The grooves closest to the edges were not considered for the grain size analysis, as potentially subject to problems due to the edge effect. Furthermore, again to avoid these problems, only the central part of the rock sample analysed with ILCM was considered, i.e. the non-coloured portion observable in Figs. 10 and 11. In detail, the debris of 10 acquisition grooves performed in different levels on marble and that obtained from 24 grooves performed in Luserna gneiss were classified. In both cases, it was found that the samples had common characteristics: basically, flattened rock chips of different sizes and a high percentage, on the total, of pulverised rock. The choice of sieves (ASTM series) was made on the basis of the procedure necessary for the definition of the Coarseness Index (CI): it is a dimensionless number that provides a comparative measure of the size and distribution of the debris produced (McFeat-Smith and Fowell 1977). It was originally proposed by Roxborough and Rispin (1973) and then used in several other studies (Altindağ, 2003, 2004; Tuncdemir et al. 2008; Balci 2009; Abu Bakar et al. 2014; Mohammadi et al. 2020). Roxborough and Rispin (1973) calculated the CI as the sum of the cumulative weight percentages retained on each sieve used. Therefore, high values of CI correspond to a larger average particle size and lower rock fragmentation. In this study, the calculation of this index was properly revised as reported in Table 6. Compared to the original approach, CI calculation referred to the volume of the fragments. Moreover, different size fractions were considered according to the aim to analyse only the coarse portion of the debris.

Then, a column with the following sizes was assembled: 25, 8, 2, 0.5 and $0.125 \mathrm{~mm}$.

The execution of the tests allowed, first of all, to carry out an assessment of the size of the debris (Fig. 12). By neglecting any losses due to sieving operations, the total mass of marble samples was 
Table 6 Example of coarseness index (CI) calculation in this study

\begin{tabular}{lcl}
\hline Size fraction $(\mathrm{mm})$ & Retained $(\%)$ & Cumulative retained $(\%)$ \\
\hline+100 & 1.4 & 1.4 \\
$-100+75$ & 3.5 & 4.9 \\
$-75+25$ & 46.8 & 51.7 \\
$-25+10$ & 25.6 & 77.3 \\
-10 & 22.7 & 100.0 \\
Total & 100.00 & $\mathrm{CI}=235.2$ \\
\hline
\end{tabular}

$1541.26 \mathrm{~g}$, and that of Luserna samples was $1781.64 \mathrm{~g}$.

The main difference is due to the coarser distribution of marble debris. In fact, the percentage of retained on the sieves with an opening of $25.4 \mathrm{~mm}$ is around $36 \%$, whereas it is practically zero in the gneiss. Another difference concerns the material held in the sieve with $8 \mathrm{~mm}$ mesh, where the percentage of gneiss is double compared to marble. The high percentage of chips held in an ASTM-\#8 sieve depends on the typical layered structure of the gneiss, which entails a reduced pulverisation of the rock, which is instead relevant in the case of marble. In fact, if in the case of gneiss, the values of the percentage retained in the last four sieves tend to decrease constantly, in marble there is a high amount of material retained in the last two classes $(0.125$ and $<0.125 \mathrm{~mm}$ ). The analysis of the percentage dispersion of retained for each sample also shows that it is large for the higher classes, while it is low for the others. This aspect can be justified on the basis of an experimental study by Jeong and Jeon (2018) whose results show that, as the depth of penetration increases, the chips become larger and at the same time have a wider particle size distribution.
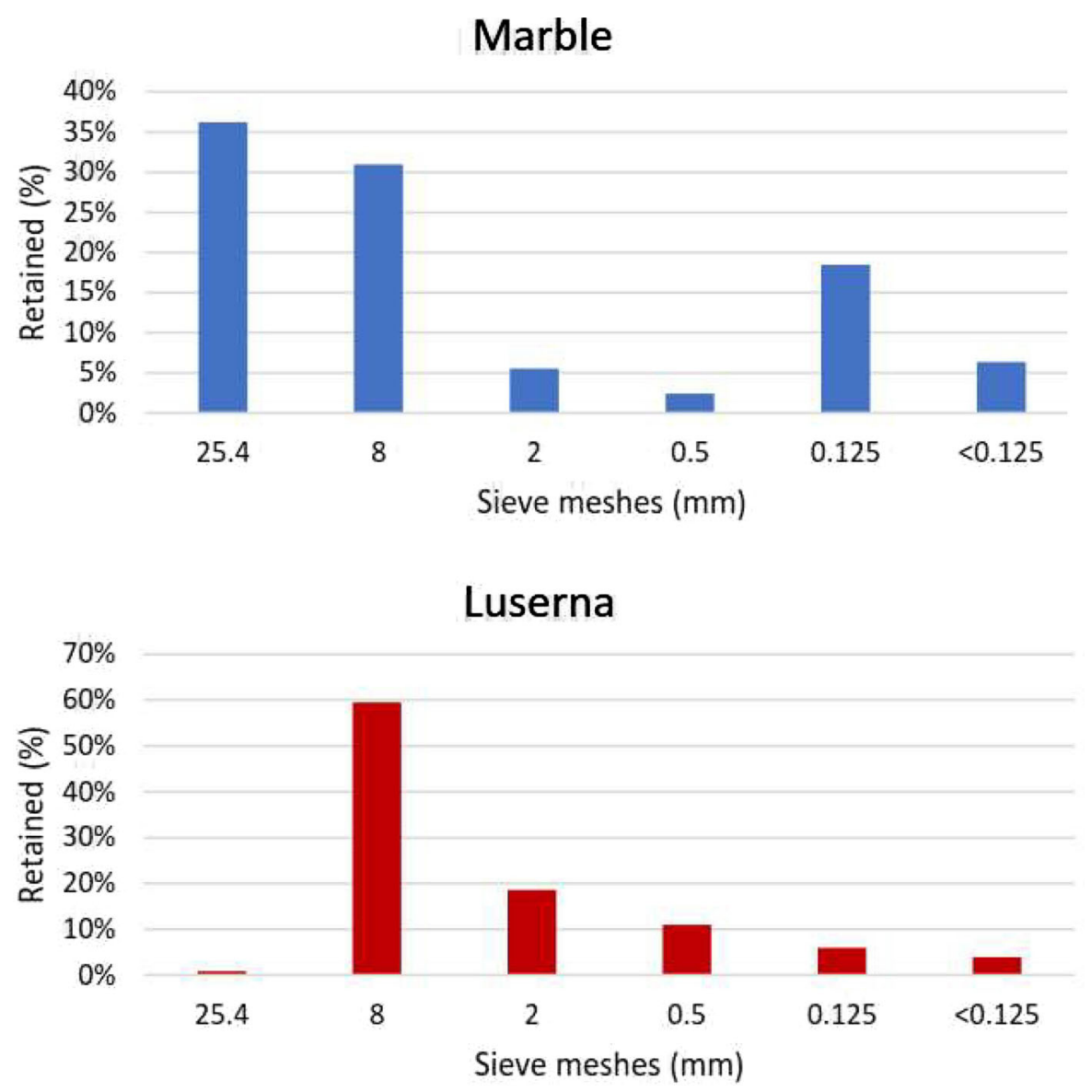

Fig. 12 Size distribution of the debris analysed (top: Carrara marble; bottom: Luserna gneiss) 
The results obtained from ILCM tests performed on Carrara marble and Luserna gneiss are summarised in Table 7. Each value is indicative of a single cutting geometry and, except for the peak forces, it was obtained by averaging the results of the data cuts within the cutting level to be assessed. The peak forces (i.e. $F_{N \max }$ and $F_{R \max }$ ) have instead the highest values of the parameter for each cutting level. The standard deviations of $F_{N}$ and $F_{R}$ are also reported. On this basis, the overall tested length for each cutting geometry was $600 \mathrm{~mm}$ (2 data cuts) in the marble sample and $1200 \mathrm{~mm}$ (4 data cuts) in the Luserna sample.

The relationship of normal and peak normal cutter force with the cutting penetration for the two rock samples tested is shown in Fig. 13. $F_{\mathrm{N}}$ shows, for each rock sample, a strong linear positive relationship with p. The $F_{\text {Nmax }}$ is more affected by local variations and hence tends to increase with increasing $\mathrm{p}$, but with a less strong linear correlation.

Due to the different mechanical properties, Luserna gneiss requires, for a given cutting penetration, higher $\mathrm{F}_{\mathrm{N}}$ and $\mathrm{F}_{\mathrm{Nmax}}$ compared to Carrara marble, despite a lower cut spacing. In particular, $\mathrm{F}_{\mathrm{N}}$ shows an increase between 20 and 30\% from marble to gneiss; however, should the cut spacing be the same, a higher difference would be expected.

The slope of the linear trendlines of the peak normal force is quite different between the two stones tested. In particular, the $\mathrm{F}_{\mathrm{Nmax}}$ trendline in the Luserna sample shows a gradient approximately double compared to that of marble, proving that a higher increase of $\mathrm{F}_{\mathrm{Nmax}}$ is expected in gneiss with increasing $\mathrm{p}$. On this basis, the limited cutting penetration chosen for the test on the Luserna sample actually allowed not to exceed the recommended cutter load capacity.

The high values of standard deviation of $\mathrm{F}_{\mathrm{N}}$ (around $30 \%$ of the average value) show that rock cutting by disc tools is a dynamic process that involves a continuous variation of the cutting forces acting on the disc. Luserna gneiss shows on average a slightly higher relative standard deviation $(31.3 \%)$ compared to Carrara marble (29.5\%). This can be attributed to the greater heterogeneity of the components of gneiss (metamorphic polycrystalline rock) compared to marble, which is homogeneous and almost $100 \%$ made up of a single component (calcium carbonate).

The relationship of normal and peak rolling cutter force with the cutting penetration is shown in Fig. 14 . Luserna gneiss shows, for a given cutting penetration, rolling cutter forces higher than those registered in Carrara marble, and the positive relationship with $p$ is almost perfect both for $F_{R}$ and $F_{R \max }$, as proved by the determination coefficients of their linear trendlines. The marble sample shows a strong linear positive relationship between $F_{R}$ and $p$, whereas a weaker linear relationship is observed between $F_{R \max }$ and $p$.

The $F_{R}$ linear trendlines show a similar gradient in both samples, whereas the $\mathrm{F}_{\mathrm{Rmax}}$ linear trendline in the

Table 7 Summary of results obtained from ILCM tests on Carrara marble and Luserna gneiss ( $C c$ cutting coefficient, $C I$ coarseness index, $P I$ penetration index, $V$ volume of the debris, SE specific energy)

\begin{tabular}{|c|c|c|c|c|c|c|c|c|c|c|c|c|}
\hline Sample & $\begin{array}{l}\mathrm{p} \\
(\mathrm{mm})\end{array}$ & $\begin{array}{l}\mathrm{s} \\
(\mathrm{mm})\end{array}$ & $\begin{array}{l}\mathrm{s} / \mathrm{p} \\
(-)\end{array}$ & $\mathrm{F}_{\mathrm{N}}(\mathrm{kN})$ & $\begin{array}{l}\mathrm{F}_{\mathrm{Nmax}} \\
(\mathrm{kN})\end{array}$ & $\mathrm{F}_{\mathrm{R}}(\mathrm{kN})$ & $\begin{array}{l}F_{\text {Rmax }} \\
(\mathrm{kN})\end{array}$ & $\begin{array}{l}\mathrm{Cc} \\
(-)\end{array}$ & $\begin{array}{l}\text { CI (- } \\
\text { ) }\end{array}$ & $\begin{array}{l}\mathrm{PI}(\mathrm{kN} / \\
\mathrm{mm})\end{array}$ & $\begin{array}{l}\mathrm{V} \\
\left(\mathrm{cm}^{3}\right)\end{array}$ & $\begin{array}{l}\mathrm{SE}(\mathrm{MJ} / \\
\left.\mathrm{m}^{3}\right)\end{array}$ \\
\hline \multirow{5}{*}{$\begin{array}{c}\text { Carrara } \\
\text { marble }\end{array}$} & 3.5 & 40 & 11.4 & $26.8 \pm 7.5$ & 52.1 & $4.2 \pm 1.0$ & 8.4 & 0.16 & 388.7 & 7.7 & 38.7 & 33.0 \\
\hline & 4.0 & 40 & 10.1 & $27.2 \pm 8.5$ & 55.0 & $4.5 \pm 1.4$ & 9.0 & 0.17 & 419.4 & 6.9 & 52.2 & 39.5 \\
\hline & 4.5 & 40 & 9.0 & $29.3 \pm 9.5$ & 59.2 & $5.0 \pm 1.4$ & 8.7 & 0.17 & 460.5 & 6.6 & 59.6 & 25.2 \\
\hline & 4.9 & 40 & 8.1 & $32.4 \pm 9.4$ & 54.4 & $5.9 \pm 1.5$ & 9.9 & 0.18 & 460.9 & 6.6 & 75.3 & 23.5 \\
\hline & 5.5 & 40 & 7.3 & $33.4 \pm 8.9$ & 67.3 & $6.3 \pm 1.5$ & 11.2 & 0.19 & 447.1 & 6.1 & 73.8 & 25.9 \\
\hline \multirow{6}{*}{$\begin{array}{l}\text { Luserna } \\
\text { gneiss }\end{array}$} & 1.8 & 30 & 16.3 & $25.7 \pm 7.5$ & 54.4 & $3.5 \pm 1.1$ & 7.8 & 0.14 & 416.5 & 14.0 & 18.2 & 59.4 \\
\hline & 2.3 & 30 & 12.9 & $29.1 \pm 10.0$ & 74.5 & $4.1 \pm 1.4$ & 8.6 & 0.14 & 425.1 & 12.5 & 26.4 & 48.4 \\
\hline & 2.9 & 30 & 10.5 & $32.3 \pm 10.3$ & 77.3 & $4.8 \pm 1.5$ & 10.3 & 0.15 & 426.9 & 11.3 & 27.3 & 54.6 \\
\hline & 3.3 & 30 & 9.0 & $32.5 \pm 10.1$ & 68.2 & $5.3 \pm 1.8$ & 11.4 & 0.16 & 424.7 & 9.8 & 34.7 & 46.3 \\
\hline & 3.7 & 30 & 8.0 & $35.4 \pm 11.6$ & 79.5 & $6.0 \pm 1.9$ & 13.1 & 0.17 & 438.7 & 9.5 & 39.1 & 45.8 \\
\hline & 4.3 & 30 & 7.0 & $36.7 \pm 10.4$ & 87.1 & $6.5 \pm 2.0$ & 14.3 & 0.18 & 419,2 & 8.6 & 36.4 & 54.1 \\
\hline
\end{tabular}



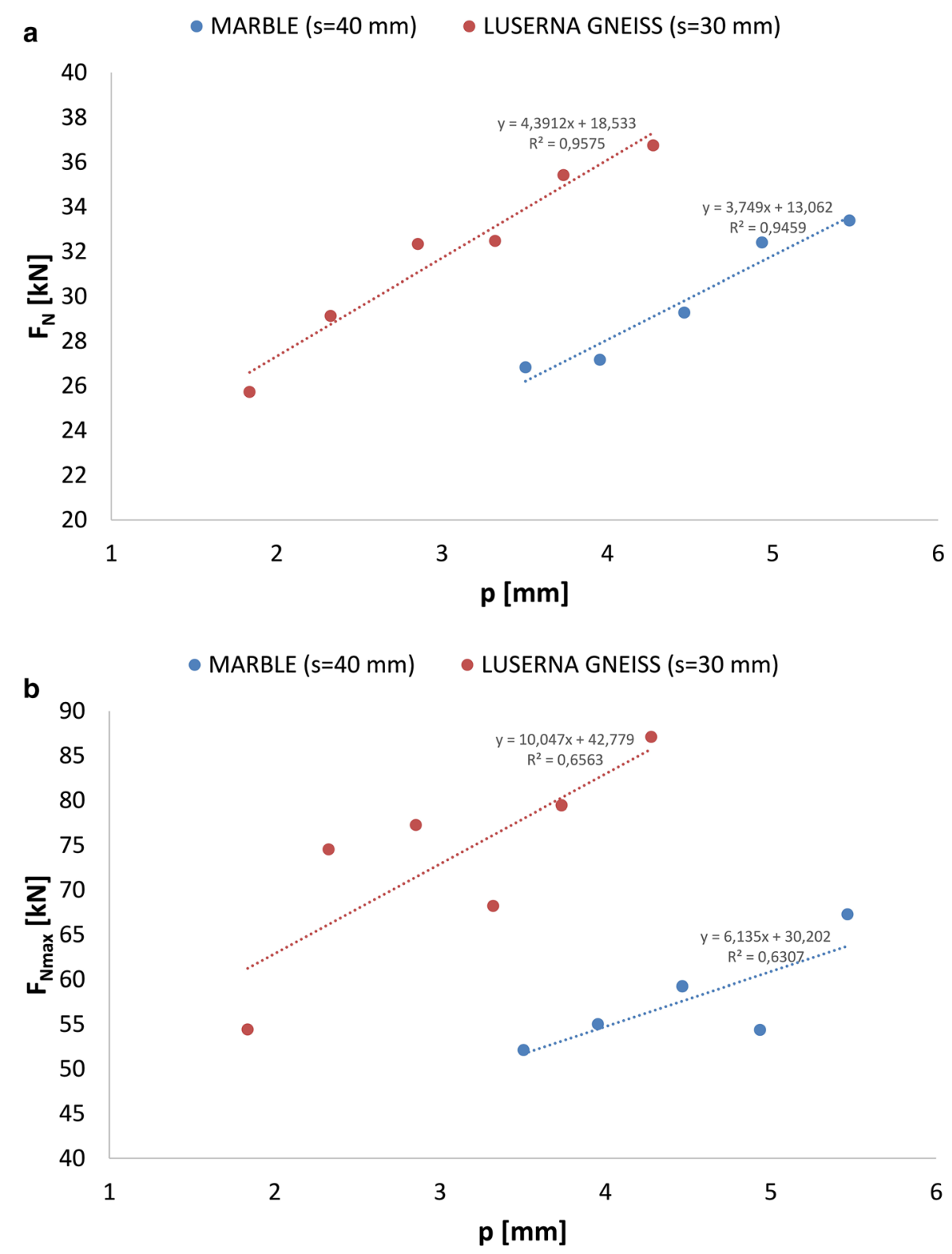

Fig. 13 Relationship of average (a) and peak (b) normal cutter force with cutting penetration p obtained from ILCM tests on Carrara marble and Luserna gneiss

Luserna sample shows once again a gradient considerably higher than in Carrara marble.

The difference in terms of relative standard deviation of $F_{R}$ between the two samples is more marked compared to that of $\mathrm{F}_{\mathrm{N}}$. In particular, Carrara marble shows on average a relative standard deviation around $27 \%$, whereas a value higher than $32 \%$ is on average noticed in Luserna gneiss.
Figure 15 shows the relationship of $\mathrm{F}_{\mathrm{Nmax}} / \mathrm{F}_{\mathrm{N}}$ ratio and $F_{R \max } / F_{R}$ ratio with cutting penetration. Luserna gneiss shows slightly higher ratios compared to Carrara marble. $\mathrm{F}_{\mathrm{Nmax}} / \mathrm{F}_{\mathrm{N}}$ ratio ranges between 2.1 and 2.6 in the Luserna sample, whereas it is around 2 in the marble sample, except for one data point. $F_{R \max } / F_{R}$ ratio is instead quite steady between 2.1 and 2.2. in the Luserna gneiss, whereas it ranges between 1.7 and 2 in Carrara marble. 
Fig. 14 Relationship of average (a) and peak (b) rolling cutter force with cutting penetration obtained from ILCM tests on Carrara marble and Luserna gneiss
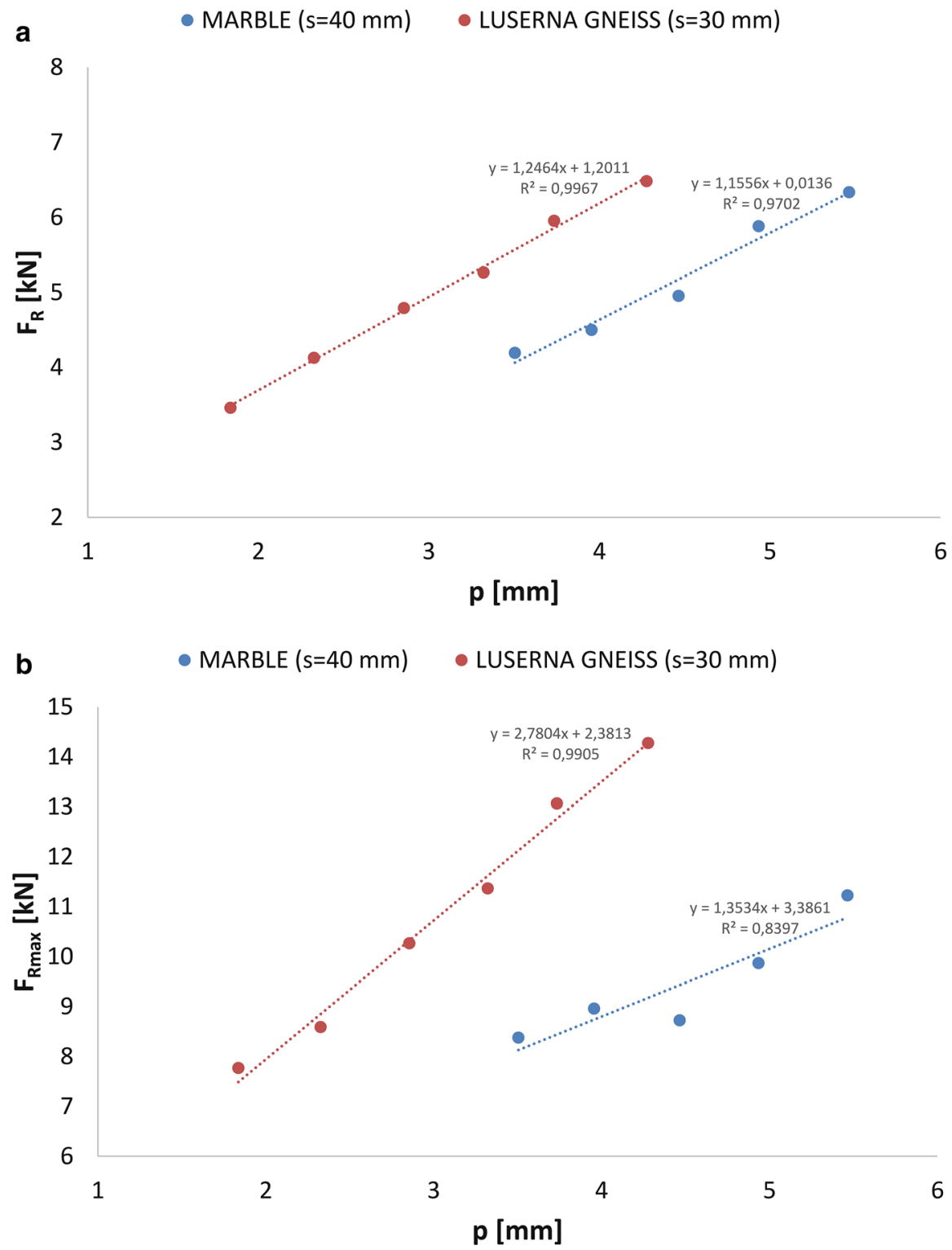

The relationship between cutting coefficient $\mathrm{Cc}$ $\left(\mathrm{Cc}=\mathrm{F}_{\mathrm{R}} / \mathrm{F}_{\mathrm{N}}\right)$ and penetration is shown in Fig. 16. In particular, as noted by Rostami and Ozdemir (1993), Pan et al. (2018) and Gertsch et al. (2007), Cc increases with increasing $\mathrm{p}$. The linear relationship is almost perfect, and the gradient is very similar in both samples. However, Luserna gneiss shows, for a given cutting spacing, a slightly higher $\mathrm{Cc}$ than that of Carrara marble.

The primary aim of the study was to test the improvements made to the ILCM. The rock types tested are not directly linked to current tunnelling projects: however, some results of these tests can be compared with some of those obtained from the TBM excavation of the Maddalena exploratory tunnel (e.g. Rispoli et al. 2018; Rispoli 2018), which is one of the four exploratory tunnels under the Lyon-Turin highspeed rail project. Indeed, this tunnel crossed the aplitic gneiss of the Ambin complex (AMC), which presents massive rock masses and has the same lithology and very similar mechanical properties to the Luserna gneiss.

By comparing the results obtained by ILCM tests with on-site observations, some differences are 
a

- MARBLE $(s=40 \mathrm{~mm}) \quad$ LUSERNA GNEISS $(s=30 \mathrm{~mm})$
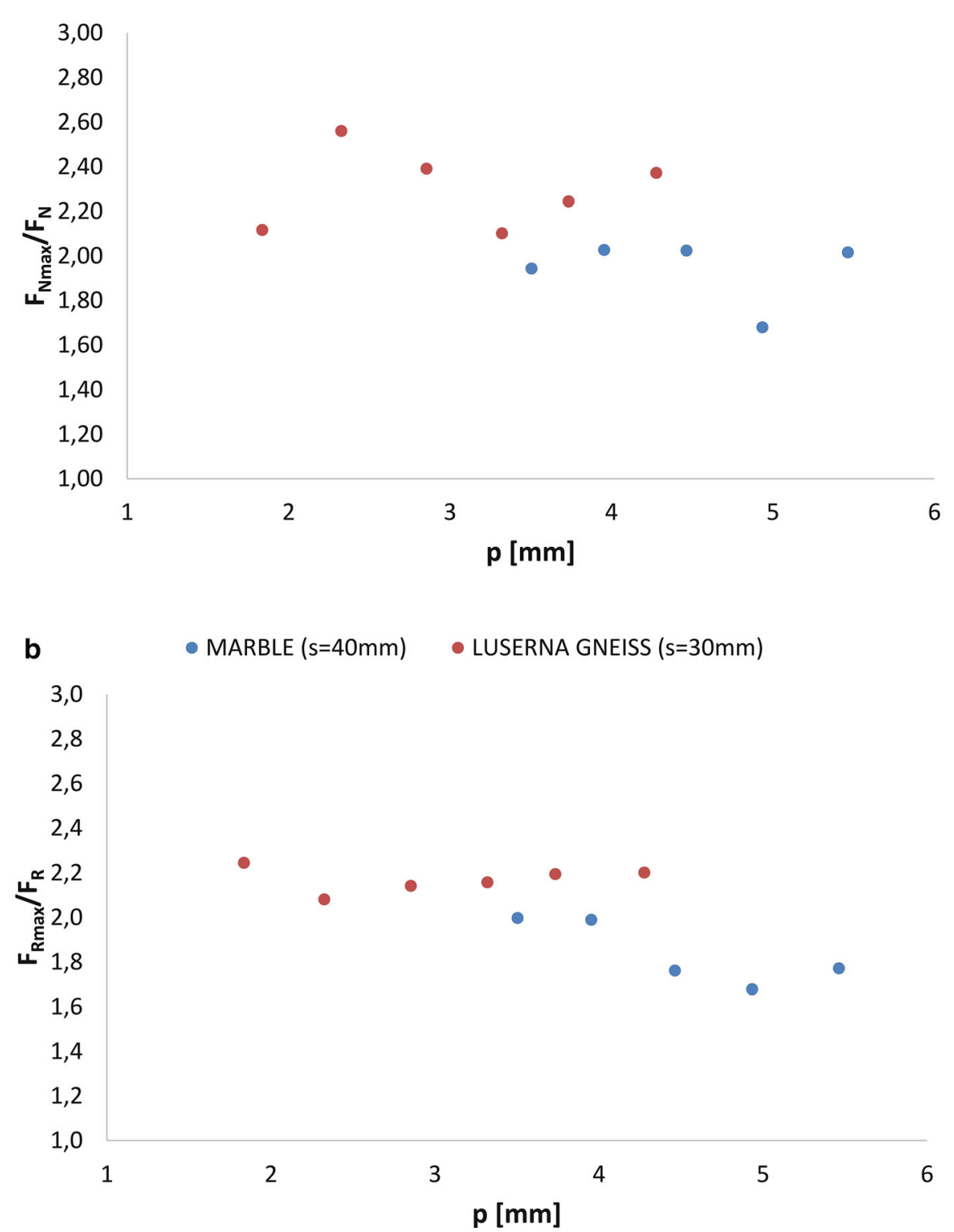

Fig. 15 Relationship of $\mathrm{F}_{\mathrm{Nmax}} / \mathrm{F}_{\mathrm{N}}$ ratio (a) and $\mathrm{F}_{\mathrm{Rmax}} / \mathrm{F}_{\mathrm{R}}$ ratio (b) with cutting penetration obtained from ILCM tests on Carrara marble and Luserna gneiss

observed. In fact, the Cc obtained from TBM excavation in the AMC gneiss, for a cutting penetration of $2.2 \mathrm{~mm}$ (e.g. average rate of penetration (ROP)- in AMC), is estimated around 0.035 , whereas it reaches around 0.14 in ILCM tests on Luserna gneiss. Such gap, assuming that the mechanical and structural properties of the two rocks involved are similar, is likely due to variations in terms of cutting and cutter geometry. The on-site cutter spacing, as well as the on- site cutter diameter, was in fact more than twice that used in ILCM tests.

Figure 17 shows the relationship of penetration index PI $\left(\mathrm{PI}=\mathrm{F}_{\mathrm{N}} / \mathrm{p}\right)$ with cutting penetration and average normal cutter force. In particular, PI shows a strong negative linear relationship with $p$ and $F_{N}$ in Luserna gneiss, whereas it tends to decrease with a weaker gradient in Carrara marble. These observations clearly show how the field penetration index (FPI) can 


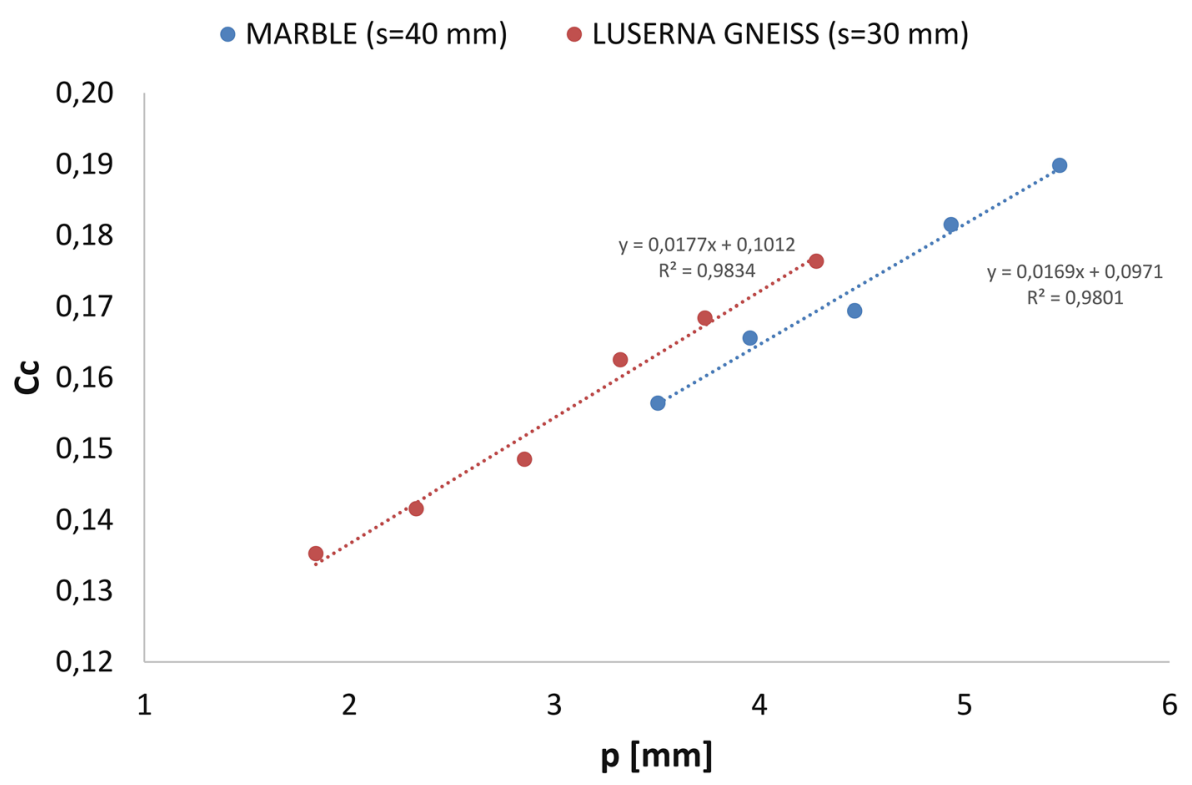

Fig. 16 Relationship between cutting coefficient and cutting penetration obtained from ILCM tests on Carrara marble and Luserna gneiss

be affected by the operating level of the machine, proving how this index may provide misleading results if applied with significantly different machine operating levels, as noted by Farrokh et al. (2012). The PI values obtained in Luserna gneiss are, as expected, considerably lower than those observed in the on-site excavation of the AMC gneiss, where an average FPI of around $140 \mathrm{kN} / \mathrm{mm}$ was registered (Cardu et al. 2017b) In fact, the different diameter and edge profile of the cutter, as well as the lower cutting spacing, provide a drastic decrease of the $\mathrm{F}_{\mathrm{N}}$ required in ILCM tests, for a given cutting penetration. Moreover, the threshold value of the thrust was not exceeded in AMC excavation, resulting in a further increase of the FPI values recorded on-site. As for the PI trend, a negative relationship between FPI and ROP was observed onsite, according to the ILCM results, whereas a slight positive trend was obtained between FPI and $\mathrm{F}_{\mathrm{N}}$. Such difference is attributable, contrary to what happens in laboratory tests, to the properties of the rock mass that can vary during the excavation on-site, and an increase in the thrust of the machine is generally observed when the rock mass boreability decreases.

The relationship of the debris volume $\mathrm{V}$ and the specific energy SE with cutting penetration is shown in Fig. 18. The debris volume assumes a rather linear positive trend with $\mathrm{p}$ in both samples tested. Marble shows, as a result of a greater spacing between the grooves, a debris volume higher than that of Luserna, for a given cutting penetration and testing length. A greater debris volume produced in the marble sample, as well as a lower $F_{R}$ required, results in a lower consumption of SE compared to the Luserna sample.

Figure 19 shows the relationship between specific energy SE and spacing/penetration ratio (s/p), allowing the determination of $(\mathrm{s} / \mathrm{p})_{\mathrm{opt}}$ for the two samples tested. Carrara marble shows a minimum value of SE with an s/p around 8, whereas Luserna gneiss shows a more ambiguous trend. In particular, a minimum $\mathrm{SE}$ is observed for (s/p) around 7-8; despite this, an (s/p) opt lower than 16 can be expected for Luserna gneiss by referring to the observed SE trend.

A further important aspect highlighted in Fig. 18 concerns the relationship between the coarseness index (CI) and the specific excavation energy (SE).

The trend shows how, with the increase of CI, the excavation efficiency is higher as the specific energy decreases (Jeong and Jeon 2018). This aspect, observing the slope of the straight lines interpolating the points representing the average values of the debris of the two typologies of rock samples, is more evident in the case of the Luserna gneiss.

The trend for both rocks, however, confirms what was stated by Roxborough and Rispin (1973) and Gong et al. (2007), namely, the inverse proportionality between $\mathrm{CI}$ and SE. 


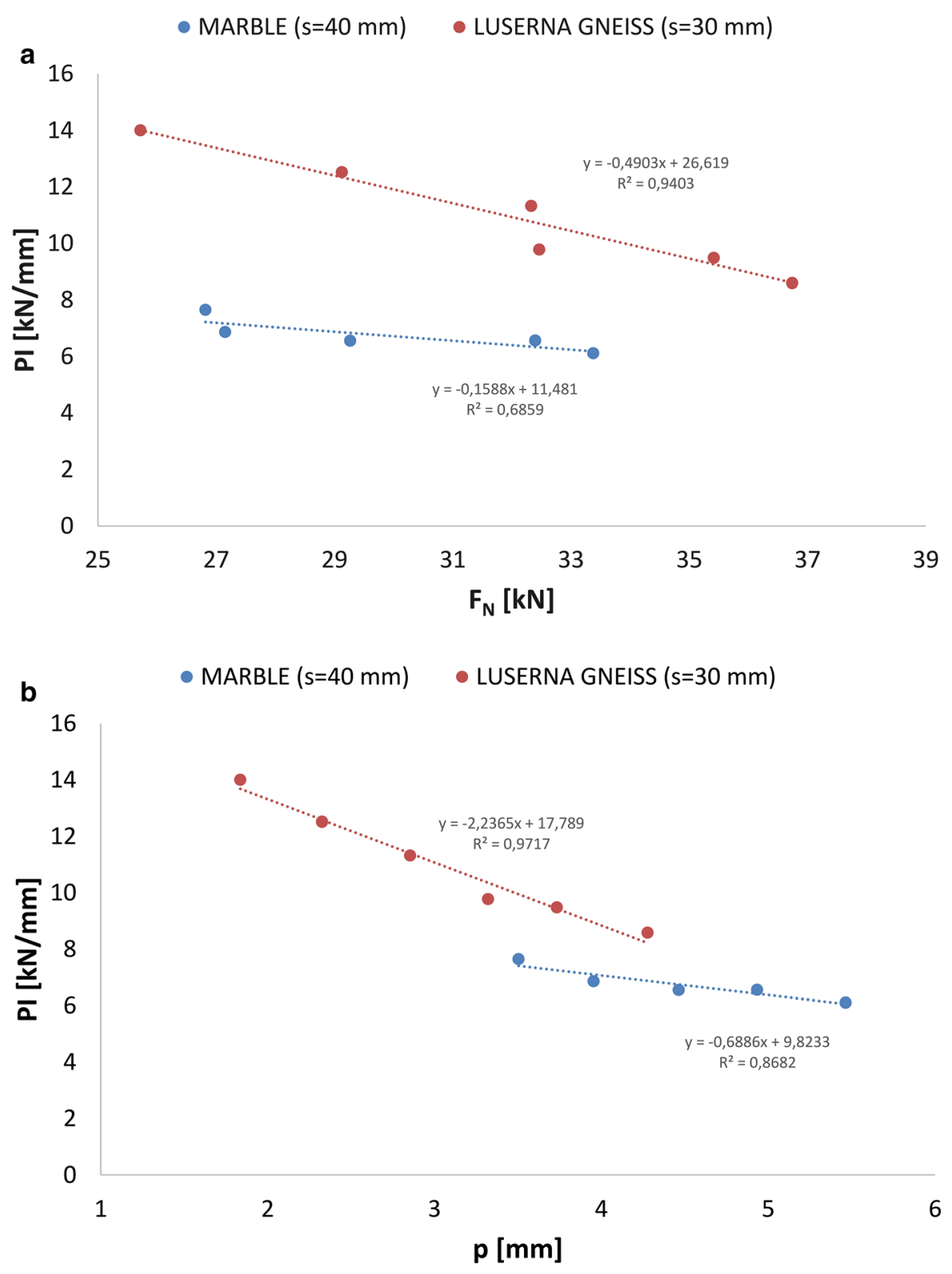

Fig. 17 Relationship of penetration index with cutting penetration (a) and average normal cutter force (b) obtained from ILCM tests on Carrara marble and Luserna gneiss

\section{Parameters Attained from the Real Case (Maddalena Exploratory Tunnel)}

Although the rock types tested are not directly linked to current tunnelling project, some results of the tests can be compared with those obtained from the TBM excavation of the $7 \mathrm{~km}$ long Maddalena tunnel (e.g. Rispoli et al. 2018; Rispoli 2018), completed in 2017, which is one of the four exploratory tunnels under the
Lyon-Turin high-speed rail project. Indeed, along the first $\mathrm{km}$ this tunnel crossed the aplitic gneiss of the Ambin complex (AMC), where the same lithology and mechanical properties very similar to Luserna gneiss are found.

The excavation was carried out by a $6.3 \mathrm{~m}$ diameter Robbins "Main Beam" Gripper TBM, whose characteristics are summarised in Table 8. 

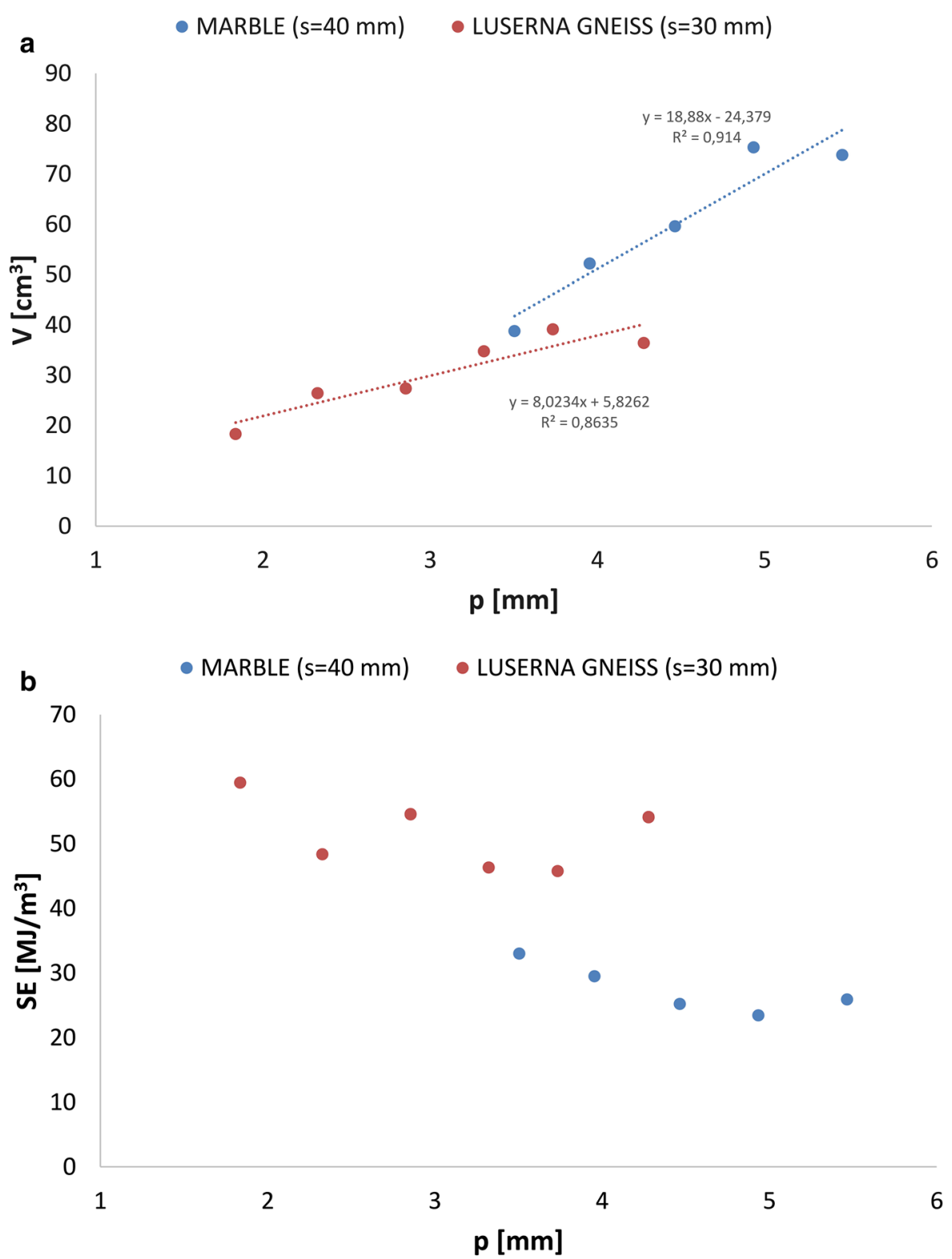

Fig. 18 Relationship of debris volume (a) and specific energy (b) with cutting penetration obtained from ILCM tests on Carrara marble and Luserna gneiss

The tunnel crosses two main lithological units: the Ambin Complex (AMC) for around $1 \mathrm{~km}$, and the Clarea Complex (CLR) for almost $6 \mathrm{~km}$, with a transition zone (AMD) of around $200 \mathrm{~m}$. In detail, it can be noticed that:

- AMC unit has the best mechanical properties. The rock mass is massive, with RMR and GSI average values over 70; joints are quite spaced and oriented to favour the tunnel stability. AMC also presents an overburden significantly lower than the other units.

- AMD shows quite variable mechanical properties, generally lower than AMC. Rock mass properties of this unit tend to decrease when the chainage increases, showing that AMD is a transition zone between the two main lithological unit crossed by the tunnel. 

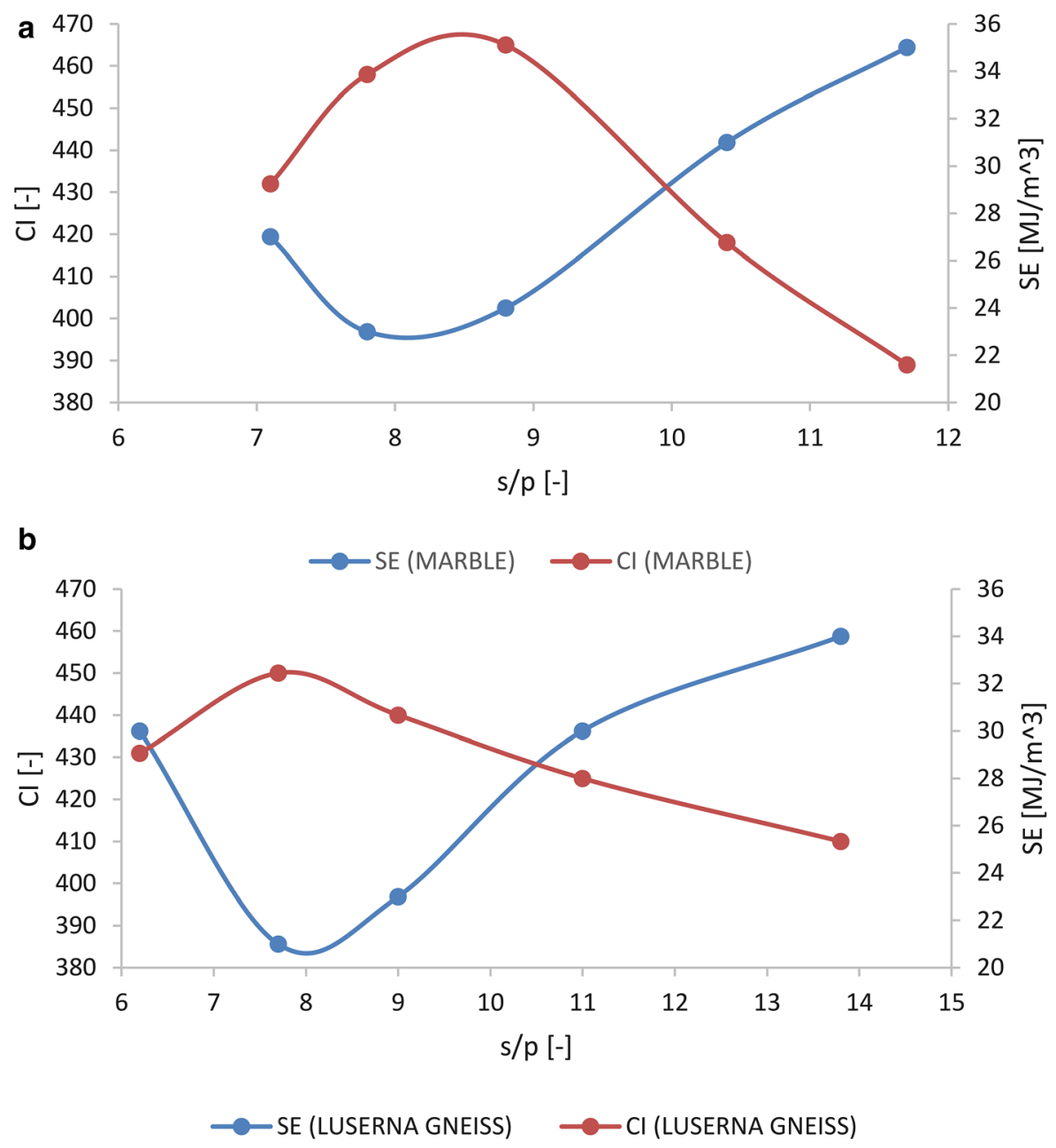

Fig. 19 Relationship between specific energy SE, coarseness index CI and spacing/penetration ratio obtained from ILCM tests on Carrara marble (a) and Luserna gneiss (b)

Table 8 Main technical characteristics of the TBM

\begin{tabular}{ll}
\hline Recommended cutterhead thrust & $12,800 \mathrm{kN}$ \\
Maximum machine thrust & $13,700 \mathrm{kN}$ \\
Cutterhead power & $2,202.8 \mathrm{~kW}$ \\
Cutterhead torque & $2,082.9 \mathrm{kN} \cdot \mathrm{m}$ \\
Cutterhead speed & $0-10.8 \mathrm{rpm}$ \\
Thrust cylinder stroke & $1830 \mathrm{~mm}$ \\
Gripper total force & $36,400 \mathrm{kN}$ \\
Numbers of disc cutters & $43(2 \mathrm{for}$ overcutting) \\
Disc cutters size & $17^{\prime \prime}(431.8 \mathrm{~mm})$ \\
Average cutter spacing & $76.8 \mathrm{~mm}$ \\
\hline
\end{tabular}

- RMR values in CLR are generally lower than 60, the joints are less spaced, with an unfavourable orientation. Moreover, overburden is substantially higher.

The distribution of net performance, excavation parameters, rock mass boreability and cutting efficiency registered is given in Table 9, and it's discussed below, with a special focus on the two main lithological units (AMC and CLR) crossed.

The average values of $F_{N}$ in AMC and CLR are significantly different, showing two different machine operating levels: the average $\mathrm{F}_{\mathrm{N}}$ in AMC is around 261 $\mathrm{kN}$, close to the thrust limit of the cutters employed; this shows the very good mechanical behaviour of the rock mass encountered. 
Table 9 Summary of the distribution of excavation parameters, net performance, rock mass boreability and cutting efficiency parameters registered during the excavation of the

\begin{tabular}{|c|c|c|c|c|c|c|c|c|c|c|}
\hline Lithology & Parameter & $\begin{array}{l}\mathrm{F}_{\mathrm{N}} \\
(\mathrm{kN})\end{array}$ & $\begin{array}{l}\mathrm{T} \\
(\mathrm{kN} \cdot \mathrm{m})\end{array}$ & $\begin{array}{l}\mathrm{RPM}(\mathrm{rev} / \\
\mathrm{min})\end{array}$ & $\begin{array}{l}\mathrm{P} \\
(\mathrm{kW})\end{array}$ & $\begin{array}{l}\mathrm{PR}(\mathrm{m} / \\
\mathrm{h})\end{array}$ & $\begin{array}{l}\mathrm{ROP}(\mathrm{mm} / \\
\text { rev) }\end{array}$ & $\begin{array}{l}\text { FPI (kN/cutter/ } \\
\mathrm{mm} / \mathrm{rev})\end{array}$ & $\begin{array}{l}\mathrm{SE}(\mathrm{MJ} / \\
\left.\mathrm{m}^{3}\right)\end{array}$ & $\begin{array}{l}\mathrm{s} / \mathrm{p} \\
(-)\end{array}$ \\
\hline \multirow[t]{2}{*}{$\mathrm{AMC}$} & Average & 260.8 & 584.3 & 9.0 & 544.8 & 1.2 & 2.2 & 143.0 & 59.5 & 41.9 \\
\hline & St. dev & 17.1 & 138.4 & 0.6 & 121.9 & 0.5 & 1.0 & 54.6 & 13.2 & 15.9 \\
\hline \multirow[t]{2}{*}{ AMD } & Average & 234.3 & 659.4 & 8.6 & 590.9 & 1.5 & 2.8 & 93.2 & 50.1 & 29.6 \\
\hline & St. dev & 48.3 & 136.6 & 0.6 & 143.4 & 0.4 & 0.8 & 41.5 & 14.4 & 8.9 \\
\hline \multirow[t]{2}{*}{ CLR } & Average & 178.5 & 572.7 & 7.2 & 446.3 & 1.5 & 3.5 & 57.7 & 34.5 & 24.1 \\
\hline & St. dev & 46.6 & 207.4 & 1.4 & 205.8 & 0.4 & 1.1 & 28.2 & 12.6 & 7.9 \\
\hline
\end{tabular}

Maddalena exploratory (Rispoli 2018). $\mathrm{F}_{\mathrm{N}}$, normal cutter force; $\mathrm{T}$, torque; RPM, rotational cutterhead speed; PR, penetration rate; ROP, rate of penetration; FPI, field penetration index

.

As for the Field Specific Energy, AMC shows an average value of around $60 \mathrm{MJ} / \mathrm{m}^{3}$, compared to about $35 \mathrm{MJ} / \mathrm{m}^{3}$ in CLR: this shows that the excavation in AMC requires a consumption of SE that is almost twice that of CLR. $60 \%$ of the data referred to AMC are in the range between 50 and $70 \mathrm{MJ} / \mathrm{m}^{3}$, whereas $70 \%$ of the data related to CLR are between 20 and $50 \mathrm{MJ} / \mathrm{m}^{3}$.

The two main lithological units show significantly different average values of s/p: higher than 40 in AMC, compared to about 24 in CLR. This shows relevant differences in terms of cutting conditions: AMC was excavated by keeping s/p values much higher than the typical $\mathrm{s} / \mathrm{p}$ values suggested for massive rocks, namely between 10 and 20, (Ozdemir 1992; Rostami 2008; Rostami and Chang 2017), proving that the excavation of this unit did not occur in optimum cutting conditions. In fact, when s/p values are too high, the fractures that develop from the tool paths cannot interfere, and this means that several revolutions of the cutterhead are needed to allow the chip's formation. To improve the boring efficiency in AMC, an increase of ROP would be necessary; however, the excavation in AMC was performed close to the cutter load capacity. On this basis, some characteristics of the cutterhead employed were not suitable to cross the AMC unit; reasonable s/p values would be obtained by:

- Smaller cutter spacing: this would have, anyhow, implied the increase of the number of cutters and higher costs per unit volume of rock excavated. Moreover, the average cutter spacing used falls 
rock sample, similarly to the test procedure typically used in standard LCM tests.

The results obtained by ILCM tests provided relevant information about the aptitude of two lithotypes to be excavated by means of disc tools. However, some differences between on-site and laboratory cutting conditions did not allow to directly compare all the ILCM results to on-site TBM excavation, as proved by comparing the results from Luserna gneiss with those observed during the TBM excavation of the first part of the Maddalena exploratory tunnel across the aplitic gneiss of AMC, which shows characteristics similar to Luserna gneiss.

Nonetheless, on the basis of the assumptions reported in the opening section, the optimal spacing/ penetration ratio should be not less affected by the scale effect involved and can therefore provide reliable information about the on-site optimal cutting condition in massive rock mass. In this regard, the optimal cutting condition of the marble sample was obtained for ( $\mathrm{s} / \mathrm{p})_{\mathrm{opt}}$ around 8 . As for Luserna gneiss, although a clear $(\mathrm{s} / \mathrm{p})_{\text {opt }}$ was not defined, a value between 8 and 13 can be considered according to the results from ILCM tests, proving the low efficiency of the cutting process during the excavation of the Ambin Complex Gneiss (AMC).

Acknowledgements The authors are grateful to Montes R. and Castagnola G. for their support in carrying out experimental laboratory tests on the ILCM.

Funding Open Access funding provided by Politecnico di Torino. The authors received no specific funding for this work.

Availability of Data and Materials and Code Data will be made available on request.

\section{Compliance with Ethical Standards}

Conflict of interest The authors declare that they have no conflict of interest.

Open Access This article is licensed under a Creative Commons Attribution 4.0 International License, which permits use, sharing, adaptation, distribution and reproduction in any medium or format, as long as you give appropriate credit to the original author(s) and the source, provide a link to the Creative Commons licence, and indicate if changes were made. The images or other third party material in this article are included in the article's Creative Commons licence, unless indicated otherwise in a credit line to the material. If material is not included in the article's Creative Commons licence and your intended use is not permitted by statutory regulation or exceeds the permitted use, you will need to obtain permission directly from the copyright holder. To view a copy of this licence, visit http://creativecommons.org/licenses/by/4.0/.

\section{References}

Abu Bakar MZ, Gertsch LS, Rostami J (2014) Evaluation of fragments from disc cutting of dry and saturated sandstone. Rock Mech Rock Eng 47:1891-1903. https://doi.org/10. 1007/s00603-013-0482-8

Altindağ R (2003) Estimation of penetration rate in percussive drilling by means of coarseness index and mean particle size. Rock Mech Rock Eng 36:323-332. https://doi.org/10. 1007/s00603-003-0002-3

Altindağ R (2004) Evaluation of drill cuttings in prediction of penetration rate by using coarseness index and mean particle size in percussive drilling. Geotech Geol Eng 22:417-425. https://doi.org/10.1023/B:GEGE. 0000025043.92979 .48

Balci C (2009) Correlation of rock cutting tests with field performance of a TBM in a highly fractured rock formation: a case study in Kozyatagi-Kadikoy metro tunnel, Turkey. Tunn Undergr Space Technol 24:423-435. https://doi.org/ 10.1016/j.tust.2008.12.001

Balci C, Bilgin N (2007) Correlative study of linear small and full-scale rock cutting tests to select mechanized excavation machines. Int J Rock Mech Min Sci 44:468-476. https://doi.org/10.1016/j.ijrmms.2006.09.001

Balci C, Tumac D (2012) Investigation into the effects of different rocks on rock cuttability by a V-type disc cutter. Tunn Undergr Space Technol 30:183-193. https://doi.org/ 10.1016/j.tust.2012.02.018

Benato A, Oreste P (2015) Prediction of penetration per revolution in TBM tunneling as a function of intact rock and rock mass characteristics. Int J Rock Mech Min Sci 74:119-127. https://doi.org/10.1016/j.ijrmms.2014.12.007

Bilgin N, Balci C, Acaroglu O et al (1999) The performance prediction of a TBM in Tuzla-Dragos sewerage tunnel. In: Challenges for the 21st century. Proceedings of the world tunnel Congress '99, Oslo, June 1999, vol 2, pp 817-822

Bilgin N, Feridunoglu C, Tumac D, Cinar M, Palakci Y, Gunduz O, Ozyol L (2005) The performance of a full face tunnel boring machine (TBM) in Tarabya (Istanbul). In: Erdem, Solak (eds) Underground space use: analysis of the past and lessons for the future. Proceedings of the 31th ITAAITES world tunnel Congress, Istanbul, Turkey 2005

Bilgin N, Copur H, Balci C, Tumac D, Akgul M, Yuksel A (2008) The selection of a TBM using full scale laboratory tests and comparison of measured and predicted performance values in Istanbul Kozyatagi-Kadikoy metro tunnels. In: World tunnel Congress 2008-underground facilities for better environment and safety, India 2008, pp 1509-1517

Bilgin N, Balci C, Tumaç D et al (2010) Development of a portable rock cutting rig for rock cuttability determination. In: Rock mechanics in civil and environmental engineering-proceedings of the European rock mechanics symposium, EUROCK 2010, pp 405-408

Bilgin N, Copur H, Balci C (2013) Mechanical excavation in mining and civil industries. CRC Press, Boca Raton 
Cardu M, Rispoli A, Bilgin N (2017a) Innovazioni nello scavo meccanizzato in roccia. In: Innovazione nella progettazione, realizzazione e gestione delle opere in sotterraneo. Proceedings of the MIR 2017-16 ${ }^{\circ}$ Ciclo di Conferenze di Meccanica ed Ingegneria delle Rocce, Celid, Torino 2017, pp 55-78

Cardu M, Iabichino G, Oreste P, Rispoli A (2017b) Experimental and analytical studies of the parameters influencing the action of TBM disc tools in tunnelling. Acta Geotech 12:293-304. https://doi.org/10.1007/s11440-016-0453-9

Chang SH, Choi SW, Bae GJ, Jeon S (2006) Performance prediction of TBM disc cutting on granitic rock by the linear cutting test. Tunn Undergr Space Technol 21(3-4):271

Cho JW, Jeon S, Yu SH, Chang SH (2010) Optimum spacing of TBM disc cutters: a numerical simulation using the threedimensional dynamic fracturing method. Tunn Undergr Space Technol 25:230-244

Cho JW, Jeon S, Jeong HY, Chang SH (2013) Evaluation of cutting efficiency during TBM disc cutter excavation within a Korean granitic rock using linear-cutting-machine testing and photogrammetric measurement. Tunn Undergr Space Technol 35(4):37-54

Microsoft Company. http://www.microsoft.com. Accessed 6th Nov 2020

Copur H, Aydin H, Bilgin N, Balci C, Tumac D, Dayanc C (2014) Predicting performance of EPB TBMs by using a stochastic model implemented into a deterministic model. Tunn Undergr Space Technol 42:1-14

Entacher M, Lorenz S, Galler R (2014) Tunnel boring machine performance prediction with scaled rock cutting tests. Int $\mathrm{J}$ Rock Mech Min Sci 70:450-459. https://doi.org/10.1016/j. ijrmms.2014.04.021

Entacher M, Schuller E, Galler R (2015) Rock failure and crack propagation beneath disc cutters. Rock Mech Rock Eng 48:1559-1572. https://doi.org/10.1007/s00603-014-06612

Farrokh E, Rostami J, Laughton C (2012) Study of various models for estimation of penetration rate of hard rock TBMs. Tunn Undergr Space Technol 30:110-123. https:// doi.org/10.1016/j.tust.2012.02.012

Gertsch R, Gertsch L, Rostami J (2007) Disc cutting tests in Colorado red granite: implications for TBM performance prediction. Int J Rock Mech Min Sci 44:238-246. https:// doi.org/10.1016/j.ijrmms.2006.07.007

Gong QM, Zhao J, Jiang YS (2007) In situ TBM penetration tests and rock mass boreability analysis in hard rock tunnels. Tunn Undergr Space Technol 22:303-316. https:// doi.org/10.1016/j.tust.2006.07.003

Innaurato N, Oggeri C, Oreste PP, Vinai R (2007) Experimental and numerical studies on rock breaking with TBM tools under high stress confinement. Rock Mech Rock Eng 40:429-451. https://doi.org/10.1007/s00603-006-0109-4

Innaurato N, Oggeri C, Oreste P, Vinai R (2011) Laboratory tests to study the influence of rock stress confinement on the performances of TBM discs in tunnels. Int $\mathrm{J}$ Miner Metall Mater 18(3):253-259. https://doi.org/10.1007/ s12613-011-0431-z

Jeong H, Jeon S (2018) Characteristic of size distribution of rock chip produced by rock cutting with a pick cutter. Geomech Eng 15:811-822. https://doi.org/10.12989/gae.2018.15.3. 811
Komakli R, Balci C, Copur H, Tumac D (2020) Experimental studies using a new portable linear rock cutting machine and verification for disc cutters. Tunn Undergr Space Technol (Available online 21 November 2020, 103702). https://doi.org/10.1016/j.tust.2020.103702

Liu Q, Pan Y, Liu J et al (2016) Comparison and discussion on fragmentation behavior of soft rock in multi-indentation tests by a single TBM disc cutter. Tunn Undergr Space Technol 57:151-161. https://doi.org/10.1016/j.tust.2016. 02.021

McFeat-Smith I, Fowell RJ (1977) Correlation of rock properties and the cutting performance of tunnelling machines. In: Proceedings of the conference on rock engineering, Newcastle University, Newcastle upon Tyne 1977, pp 581-602

Mohammadi M, Hamidi JK, Rostami J, Goshtasbi K (2020) A closer look into chip shape/size and efficiency of rock cutting with a simple chisel pick: a laboratory scale investigation. Rock Mech Rock Eng 53:1375-1392. https://doi.org/10.1007/s00603-019-01984-5

Ozdemir L (1992) Mechanical excavation techniques in underground construction. Short course notebook, vol 1. Istanbul Technical University, Istanbul, pp 1-49

Pan Y, Liu Q, Peng X et al (2018) Full-scale rotary cutting test to study the influence of disc cutter installment radius on rock cutting forces. Rock Mech Rock Eng 51:2223-2236. https://doi.org/10.1007/s00603-018-1460-y

Pan Y, Liu Q, Kong X, Liu J (2019) Full-scale linear cutting test in Chongqing Sandstone and the comparison with field TBM excavation performance. Acta Geotech 14(5):1249-1268. https://doi.org/10.1007/s11440-0180702-1

Pan Y, Liu Q, Liu Q, Liu J (2020) Full-scale linear cutting tests to check and modify a widely used semi-theoretical model for disc cutter cutting force prediction. Acta Geotech 15(2):1481-1500. https://doi.org/10.1007/s11440-01900852-4

Rad PF (1975) Bluntness and wear of rolling disk cutters. Int J Rock Mech Min Sci 12:93-99. https://doi.org/10.1016/ 0148-9062(75)90003-0

Rispoli A (2013) Analisi teorico-sperimentale per l'ottimizzazione dello scavo meccanizzato con utensili a disco. M.Sc. thesis, Politecnico di Torino, Turin, Italy. (In Italian, not published)

Rispoli A (2018) Hard rock TBM excavation: performance analysis and prediction. PhD thesis, University of Turin, Italy

Rispoli A, Ferrero AM, Cardu M, and Farinetti A (2018) TBM performance assessment of an exploratory tunnel in hard rock. In: Litvinenko (ed) Geomechanics and geodynamics of rock masses. Proceedings of EUROCK 2018, vol 2. Taylor \& Francis Group, London, pp 1287-1296

Rostami J (2008) Hard rock TBM cutterhead modeling for design and performance prediction. Geomech und Tunnelbau 1:18-28. https://doi.org/10.1002/geot.200800002

Rostami J, Chang SH (2017) A closer look at the design of cutterheads for hard rock tunnel-boring machines. Engineering 3:892-904. https://doi.org/10.1016/j.eng.2017.12. 009 
Rostami J, Ozdemir L (1993) New model for performance production of hard rock TBMs. In: Proceedings-rapid excavation and tunneling conference, pp 793-809

Roxborough FF, Phillips HR (1975) Rock excavation by disc cutter. Int J Rock Mech Min Sci 12:361-366. https://doi. org/10.1016/0148-9062(75)90547-1

Roxborough FF, Rispin A (1973) Investigation into the application of picks for mechanized tunnel boring in the lower chalk. Min Eng 133(1):13

Sanio HP (1985) Prediction of the performance of disc cutters in anisotropic rock. Int J Rock Mech Min Sci Geomech Abstr 22(3):153-161

Snowdon RA, Ryley MD, Temporal J (1982) A study of disc cutting in selected British rocks. Int J Rock Mech Min Sci 19:107-121. 9062(82)91151-2

Tumac D, Balci C (2015) Investigations into the cutting characteristics of CCS type disc cutters and the comparison between experimental, theoretical and empirical force estimations. Tunn Undergr Space Technol 45:84-98

Tuncdemir H, Bilgin N, Copur H, Balci C (2008) Control of rock cutting efficiency by muck size. Int J Rock Mech Min Sci 45:278-288. https://doi.org/10.1016/j.ijrmms.2007.04. 010

Yin L, Miao C, He G, Dai F, Gong Q (2016) Study on the influence of joint spacing on rock fragmentation under TBM cutter by linear cutting test. Tunn Undergr Space Technol 57:137-144

Zou D (2016) Theory and technology of rock excavation for civil engineering. Springer, Singapore

Publisher's Note Springer Nature remains neutral with regard to jurisdictional claims in published maps and institutional affiliations. 